\title{
An Overview of 9/11 Experiences and Respiratory and Mental Health Conditions among World Trade Center Health Registry Enrollees
}

\author{
Mark Farfel, Laura DiGrande, Robert Brackbill, \\ Angela Prann, James Cone, Stephen Friedman, Deborah J. Walker, \\ Grant Pezeshki, Pauline Thomas, Sandro Galea, David Williamson, \\ Thomas R. Frieden, and Lorna Thorpe
}

\begin{abstract}
To date, health effects of exposure to the September 11, 2001 disaster in New York City have been studied in specific groups, but no studies have estimated its impact across the different exposed populations. This report provides an overview of the World Trade Center Health Registry (WTCHR) enrollees, their exposures, and their respiratory and mental health outcomes 2-3 years post-9/11. Results are extrapolated to the estimated universe of people eligible to enroll in the WTCHR to determine magnitude of impact. Building occupants, persons on the street or in transit in lower Manhattan on 9/11, local residents, rescue and recovery workers/volunteers, and area school children and staff were interviewed and enrolled in the WTCHR between September 2003 and November 2004. A total of 71,437 people enrolled in the WTCHR, for $17.4 \%$ coverage of the estimated eligible exposed population (nearly 410,000); 30\% were recruited from lists, and $70 \%$ were self-identified. Many reported being in the dust cloud from the collapsing WTC Towers (51\%), witnessing traumatic events $(70 \%)$, or sustaining an injury (13\%). After $9 / 11,67 \%$ of adult enrollees reported new or worsening respiratory symptoms, 3\% reported newly diagnosed asthma, 16\% screened positive for probable posttraumatic stress disorder (PTSD), and 8\% for serious psychological distress (SPD). Newly diagnosed asthma was most common among rescue and recovery workers who worked on the debris pile (4.1\%). PTSD was higher among those who reported Hispanic ethnicity (30\%), household income $<\$ 25,000$ $(31 \%)$, or being injured (35\%). Using previously published estimates of the total number of exposed people per WTCHR eligibility criteria, we estimate between 3,800 and 12,600 adults experienced newly diagnosed asthma and 34,600-70,200 adults experienced PTSD following the attacks, suggesting extensive adverse health impacts beyond the immediate deaths and injuries from the acute event.
\end{abstract}

KEYWORDS World Trade Center, Asthma, Respiratory symptoms, Posttraumatic stress disorder, Serious psychological distress, Population estimates of WTC disaster health outcomes, World Trade Center Health Registry (WTCHR), Environmental exposures, New York City, Children, Terrorism, WTC attacks, Epidemiology, Mental health

Farfel, DiGrande, Prann, Cone, Friedman, Walker, Pezeshki, Frieden, and Thorpe are with the New York City Department of Health and Mental Hygiene, New York, NY, USA; Brackbill and Williamson are with the Agency for Toxic Substances and Disease Registry, Atlanta, GA, USA; Thomas is with the New Jersey Medical School - UMDNJ, Newark, NJ, USA; Galea is with the School of Public Health, University of Michigan, Ann Arbor, MI, USA.

Correspondence: Mark Farfel, New York City Department of Health and Mental Hygiene, New York, NY, USA. (E-mail: mfarfel@health.nyc.gov) 


\section{INTRODUCTION}

The events of September 11, 2001 in New York City were unprecedented. Two airliners crashed into the World Trade Center (WTC) twin towers, resulting in large explosions and fires. The towers collapsed within 2 hours. Four buildings or structures collapsed later, and 32 other buildings sustained moderate to major damage. Nearly 2,800 people died, including more than 2,200 civilians, 343 firefighters, and 60 police officers. Hundreds of thousands of people were exposed to environmental contaminants and witnessed potentially traumatic events. Tens of thousands of lower Manhattan building occupants, residents, and school children were evacuated and had their lives and livelihoods disrupted for months to years afterward. An estimated 91,000 rescue workers, volunteers, construction contractors, and others arrived to work at or nearby the WTC site on 9/11 or in the days and months thereafter, shifting from rescue to recovery. ${ }^{1}$ The effort involved city, state, and federal agency employees as well as contracted workers and volunteers from all 50 states.

The collapse and burning of the WTC towers and neighboring buildings released a complex mixture of irritant dust, smoke, and gaseous materials. Most dust was an alkaline mixture of pulverized concrete, glass, plastic, paper, and wood fibers. Testing of airborne and settled dust detected the presence of heavy metals, asbestos, and other substances. ${ }^{2}$ The composition of smoke and dust deposited on indoor and outdoor surfaces varied widely by date and by location. ${ }^{3}$ In subsequent months, resuspended particulate matter and fires were the main sources of airborne contaminants.

Many studies of surviving first responders and other WTC rescue and recovery workers after 9/11 have documented high levels of respiratory symptoms, severe persistent cough ("WTC cough"), reactive airways disease, asthma, and declines in pulmonary function. ${ }^{4-12}$ These reports are consistent with animal studies showing mild to moderate pulmonary inflammation and significant increases in airway hyperresponsiveness in mice exposed to high levels of fine particulate matter from the WTC site. ${ }^{13}$ Few studies have evaluated respiratory effects among exposed individuals other than rescue and recovery workers.

The trauma of 9/11 triggered depression, anxiety, substance use, and posttraumatic stress disorder. ${ }^{14-17}$ Many survivors witnessed the death of friends and co-workers; thousands lost family members in the attacks. In the wake of the disaster, many rescue, recovery, and cleanup workers or volunteers, as well as residents, office workers, and students in lower Manhattan were subjected to daily stress that continued for months. ${ }^{18-20}$

The World Trade Center Health Registry (WTCHR) is the largest postdisaster registry in U.S. history. The WTCHR is a key public health resource to document the duration and severity of health impacts, guide decisions about medical care and other services, connect individuals to specific services, and inform response planning for future disasters. This article provides an overview of the WTCHR, the enrollees, their exposures and event experiences, and their respiratory symptoms and mental health status, based on an initial interview 2-3 years after the event.

\section{METHODS}

The WTCHR was created in July 2002 as a collaborative effort between the Agency for Toxic Substances and Disease Registry (ATSDR) and the New York City Department of Health and Mental Hygiene (NYC DOHMH). Development of eligibility criteria took 
into account proximity by time and place to the WTC attack, acute exposure to the dust and debris cloud that resulted immediately from the collapse of the towers, and chronic exposure to smoke and fumes in the vicinity of the WTC site. Four broad eligibility groups were constructed: (a) people who were present south of Chambers Street in lower Manhattan on the morning of 9/11, including building occupants, passersby, and people in transit (see map insert, Figure 1); (b) workers and volunteers involved in rescue, recovery, cleanup, and other activities at the WTC site, the Staten Island Recovery Operations Center, or on a transport barge from the WTC site for at least one shift anytime from September 11, 2001 through June 30, 2002; (c) people with a primary residence south of Canal Street in lower Manhattan on 9/11; and (d) students enrolled in and staff employed at schools (grades pre-K to 12) south of Canal Street on 9/11.

The estimated total number of people eligible for the WTCHR was calculated to be 409,492, the methods for which are published elsewhere. ${ }^{1}$ Registrants were recruited for enrollment through outreach to eligible individuals and groups, as well as local and regional media. Lists of names and associated contact information of potentially eligible persons were provided voluntarily by entities such as employers and governmental agencies. All persons originally contacted via lists were classified as "list-identified". A total of 232 lists representing 135,450 potential registrants were provided: rescue, recovery, and cleanup workers and volunteers (144 lists), building occupants (76 lists), students and school staff (nine lists), and residents of lower Manhattan (three lists). A key resource for contacting WTC building survivors was a Port Authority of New York and New Jersey list which contained 95,442 names of people who had received security clearance at WTC buildings $1-7 .{ }^{21}$ Potentially eligible persons on the lists were recruited by telephone or letter. Individuals were also contacted through a widespread advertising campaign that encouraged them to enroll by using a toll-free number or by preregistering on a WTCHR website; these individuals were contacted and interviewed over the telephone and classified as self-identified.

Data Collection Of the 71,437 baseline interviews conducted between September 2003 and November 2004 (2-3 years post-9/11), 67,527 (95\%) were completed using computer-assisted telephone interviewing (CATI) and the remaining 3,910 were completed using computer-assisted in-person personal interviewing (CAPI). The questionnaire was administered in four languages: English (95.2\%), Spanish $(1.9 \%)$, Cantonese $(1.5 \%)$, and Mandarin $(1.0 \%)$. A translation service provided by a vendor was used to interview registrants whose primary language was not one of the pretranslated languages $(n=315)$. The interviewer took actions (e.g., suggested taking a break, stopped the interview, provided a referral) if a respondent's answers or behavior indicated emotional distress.

A total of 3,100 proxy interviews were completed. For children under 18 years of age at the time of interview, parents and guardians served as proxies $(n=2,635)$. Proxy interviews were conducted for adults if the potential registrant was deceased after $9 / 11(n=157)$, seriously physically or mentally disabled or unable to respond for other reasons $(n=308)$. For eligible individuals who died after $9 / 11$, a limited number of questions (e.g., demographics, cause of death, and contact information) were completed by proxy.

The WTCHR protocol, including the baseline survey, was approved by the Institutional Review Boards of the Centers for Disease Control and Prevention and the NYC DOHMH in 2003. A Federal Certificate of Confidentiality was obtained.

The baseline survey was designed to take approximately $30 \mathrm{~min}$ to administer. The interview included: (a) informed consent; (b) determination of eligibility; (c) 


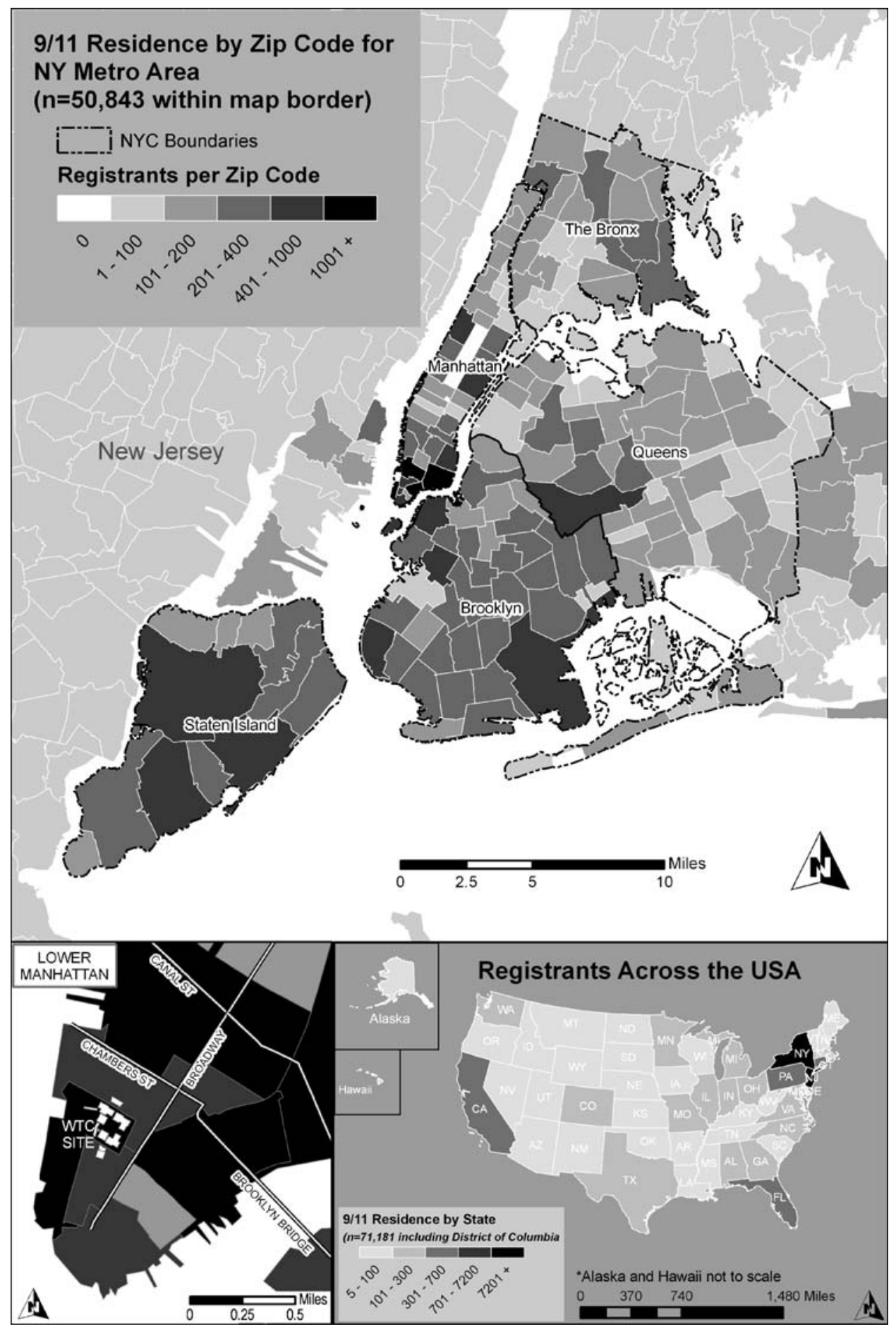

FIGURE 1. Geographic distribution of registrants' primary residences on September 11, 2001. A natural breaks classification scheme was used for the metropolitan NYC zip codes. 
demographics; (d) contact information for follow-up (including information on up to three people who would be likely to know the future whereabouts of the respondent); (e) general exposure questions (e.g., to the dust and debris cloud); (f) specific exposure assessment sections for each of the four eligibility groups; (g) 9/11 injuries; (h) physical health symptoms and conditions before and after $9 / 11$; and (i) mental health outcomes.

Health Outcomes Enrollees were asked about physical health outcomes, including: (a) injuries sustained on 9/11 ranging from eye injury or irritation to fractures, burns and concussions; (b) new or worsening respiratory symptoms at any time after $9 / 11$; (c) new or worsening nonrespiratory symptoms including hearing problems or hearing loss, severe headaches, heartburn, indigestion, or reflux; and skin rash or irritation; and (d) specific conditions diagnosed by a physician or other health professional anytime in the 2-3 years after 9/11, including newly diagnosed asthma, emphysema, hypertension, coronary heart disease, angina, heart attack, diabetes, stroke, and any cancer or malignancy. Questions about symptoms were similar to well-tested examples used in the Behavioral Risk Factor Surveillance System. ${ }^{22}$ Physical health outcomes presented in this report are restricted to post-9/11 respiratory symptoms and development of newly diagnosed asthma among persons with no history of prior asthma.

Mental health outcomes included probable posttraumatic stress disorder (PTSD) and serious psychological distress (SPD) in the 30 days prior to the interview. The Kessler-6 scale (K-6), used to determine SPD, is a psychometrically validated, epidemiologic screening measure used in the National Health Interview Survey since $1997 .{ }^{23}$ It is correlated with diagnostic measures of major depressive disorder, generalized anxiety disorder, schizophrenia, and other mental disorders. ${ }^{24}$ This paper reports the proportion of respondents who scored above a cutoff of 13 on the K-6 scale to indicate current SPD at the time of the baseline interview.

The adult interview also included the PTSD-Checklist Civilian Version (PCL), a 17-item symptom scale corresponding to the American Psychiatric Association's Diagnostic and Statistical Manual of Mental Disorders, DSM-IV criteria. ${ }^{25}$ First validated with samples of U.S. veterans, the PCL has been validated for use with civilian populations such as those exposed to assault, motor vehicle trauma, and lifethreatening or terminal illnesses. ${ }^{26-31}$ This outcome is referred to as current probable PTSD to acknowledge that self-reported screening instruments do not necessarily indicate psychopathology. ${ }^{32}$ The overall prevalence of current probable PTSD was calculated using the sum of item responses with a cutoff of 44 which classifies individuals as likely PTSD cases. Proxy interviews with parents and guardians of child enrollees included an eight-question scale derived from Hoven et al. to assess possible posttraumatic stress symptoms. ${ }^{33}$

Exposure Characterization The following information from the baseline interview was used to characterize exposures on 9/11 among all enrollees: being caught in the dust and debris cloud that resulted from the collapse of the WTC towers, time and location in the dust cloud, personally witnessing potentially traumatizing events (seeing an airplane hit either one of the WTC towers, a building collapse, people running away, someone who was injured or killed, or people falling or jumping from the WTC towers), and the types of injuries sustained on 9/11. Each eligibility group also had specific questions about exposures that occurred on or after $9 / 11$. 
Residents, for example, were asked questions about evacuation from their home, including the date of return to their home. Building occupants who evacuated a building on 9/11 were asked about the date of return to their workplace. Rescue/ recovery workers and volunteers were asked questions about their work site(s), including dates worked and types of activities. Time periods selected for analysis of post-9/11 exposures were based on characteristics developed by others using meteorological and other environmental data, including dates when rainfall occurred (e.g., September 14 and 19, 2001) and when the fires at the WTC site were extinguished (December 19, 2001). ${ }^{34}$

GIS Methods Enrollees were asked about their geographic location when they first encountered the dust cloud. Locator variables included street address $(n=15,167)$, closest cross street intersection $(\mathrm{n}=11,329)$, closest landmark $(n=10,732)$, and the closest subway stop $(n=1,119)$. Geocoding occurred only if an enrollee answered yes to being caught in the dust cloud. The New York City Department of City Planning's (DCP) Geosupport application was used for automated batch matching of street addresses. DCP's LION geodatabase (available at: http://www.nyc.gov/html/dcp/html/bytes/dwnlion.shtml) was used for geocoding street intersections and manual, interactive address matching of more complicated or incomplete address data.

A standard deviational ellipse was constructed, centered on the mean center of all the geocodable locations reported by enrollees when they first encountered the dust cloud, with its long axis in the direction of maximum dispersion and its short axis in the direction of minimum dispersion. ${ }^{35,36}$ The 1 and 2 standard deviational ellipses correspond to $68.2 \%$ and $95.4 \%$ of the geocoded data, respectively.

Data Analysis All enrollees were included in the data analysis. To maintain comparability across groups, analyses of respiratory and mental health outcomes, and total burden of illness, were restricted to adult enrollees ( $>18$ years of age) at the time of the interview, including the 157 decedents for whom only limited data were obtained via proxy interviews. This paper does include a brief summary of children's health outcomes, based on a separate analysis of the proxy interviews with parents and guardians.

SAS $^{\circledR}$ (version 9.1) was used to compute descriptive statistics and bivariate associations between health symptoms or conditions and demographic characteristics, risk factors, and selected event exposures and experiences. ${ }^{37}$ Chi-square and Cochran-Armitage tests were used to determine statistical significance. Chow and Rodgers' Euler-Venn applet software was used to create a proportional-to-size Venn diagram to depict overlap in eligibility criteria among enrollees. ${ }^{38}$

To construct estimates of the total number of adults eligible for the WTCHR who experienced illness or symptoms after the attacks, the prevalence of selfreported health problems among enrollees was applied to estimates of the total number of persons exposed for each enrollee category. ${ }^{1}$ We first categorized all exposed adults into three broad, mutually exclusive, hierarchical categories: (1) rescue and recovery workers and volunteers, (2) building occupants, passersby, and people in transit, and (3) residents south of Canal Street. For each category, two preliminary estimates were calculated: the percentage of health problems among listidentified and self-identified persons in the WTCHR, and the respective estimated denominators for each of these. For all exposed population categories and all health problems, the prevalence of self-reported disease was higher among self-identified than among list-identified persons. To construct a plausible midpoint estimate of 
total number of ill adults, we assumed that ill persons were more likely to self-enroll in the WTCHR. The midpoint estimate of persons made ill was therefore calculated as the percentage of those with health problems among list-identified persons multiplied by the total population exposed. To arrive at an upper bound estimate, we assumed that the higher percentage of symptoms among the self-identified persons was representative of the entire population and multiplied that percentage by the total population exposed. To arrive at a lower bound estimate, we assumed that even among list-identified persons, those who experienced symptoms were $50 \%$ more likely to enroll in the WTCHR than those who did not experience symptoms. To avoid implying more precision than is appropriate, estimates were rounded to the nearest hundred.

\section{RESULTS}

\section{Enrollment and Coverage by Eligibility Group}

Estimates of population sizes for each of the eligibility groups and the WTCHR coverage were reported previously. ${ }^{1}$ Both are displayed in nonmutually exclusive groups in Table 1. The total number of people eligible to enroll in the WTCHR was estimated at 409,492, of whom 71,437 enrolled. Based on these population estimates, WTCHR coverage is $17.4 \%$, ranging from $34 \%$ coverage among rescue and recovery workers to $12 \%$ among building occupants, passersby, and people in transit in lower Manhattan on the morning of $9 / 11$. Coverage is highest among police $(75 \%)$, sanitation workers $(62 \%)$, occupants of undamaged buildings near the WTC site $(52 \%)$, and occupants of damaged or destroyed buildings $(43 \%)$.

The largest group of WTCHR enrollees includes people present in lower Manhattan near the WTC site on the morning of $9 / 11(n=43,487)$, including 10,393 occupants of damaged or destroyed buildings, 19,900 occupants of other nearby buildings, and 13,194 passersby or people in transit. The registry's 30,665 rescue and recovery workers include police, firefighters, emergency medical services workers, construction or engineering personnel, and sanitation workers $(n=14,747)$ as well as volunteers affiliated with organizations and unaffiliated volunteers $(n=7,389)$. The registry also includes 14,665 lower Manhattan residents, 2,075 students (pre-K to 12 th) and 571 staff from schools in the vicinity of the WTC site.

Twenty-six percent of enrollees met more than one eligibility criterion. The greatest overlap was among building occupants, passersby, and people in transit who were also either workers $(n=7,695)$ or residents $(n=6,978)$ or both $(n=795)$ (Figure 2). Among children, many students in the registry were also residents who were present downtown on the morning of 9/11 $(n=946)$ or nonresidents but present downtown on the morning of $9 / 11(n=615)$.

Overall, $30 \%$ of enrollees were recruited from lists (list-identified), and $70 \%$ were self-identified. The percentage of list-identified enrollees ranged from $14 \%$ among students to $37 \%$ among workers.

\section{Enrollee Characteristics, Risk Factors, Exposures, and Injuries}

Figure 1 displays enrollees' primary residence on 9/11 by zip code for the New York City region and nationally. On 9/11, enrollees resided in all 50 states in the U.S. and 15 other countries. Nonetheless, almost $90 \%$ of enrollees were residents of New York State or New Jersey (Table 2). Most enrollees (65\%) were residents of New 


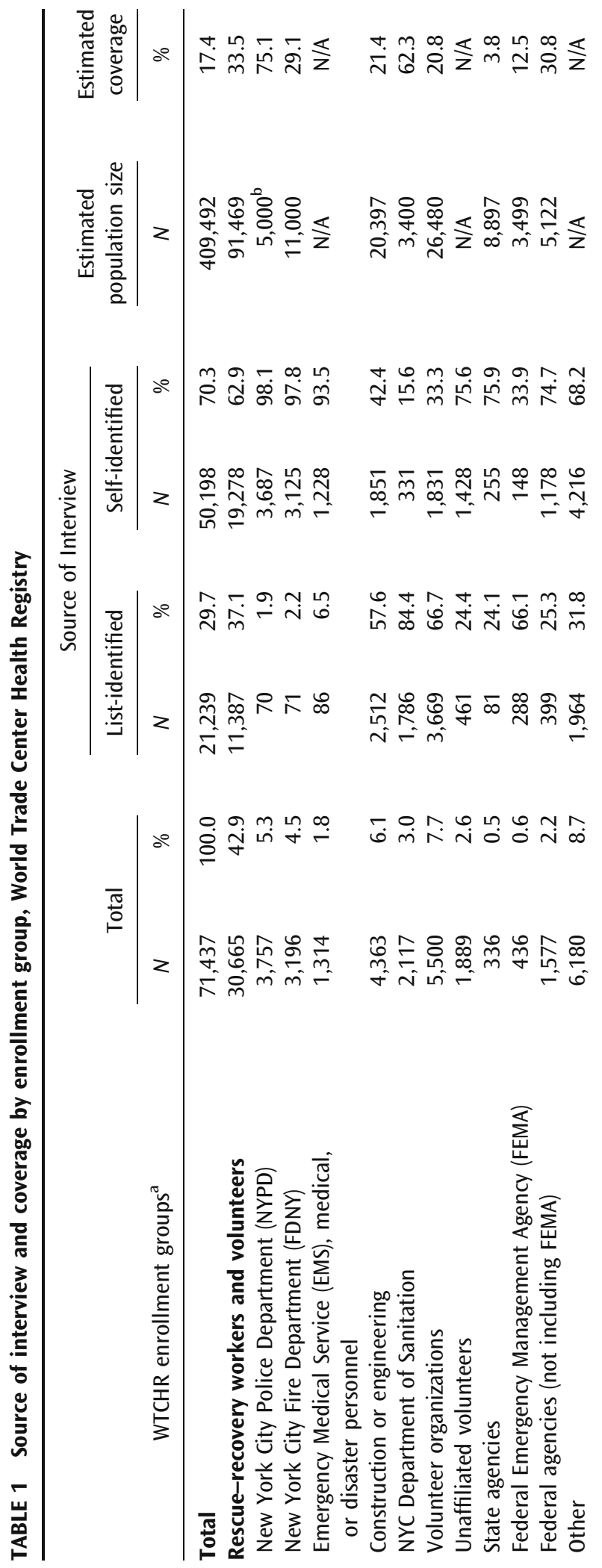




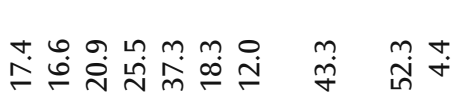

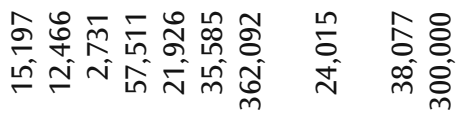

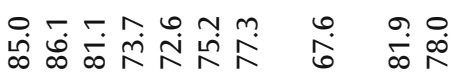

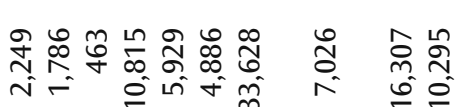

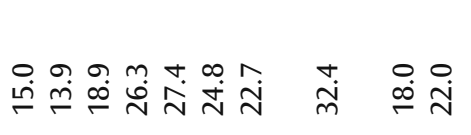

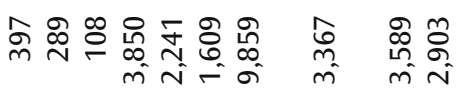

$\frac{\dot{2}}{\frac{0}{0}}$

豙

$\frac{.00}{4}$

ฮ

$\stackrel{\text { స }}{\stackrel{5}{\varpi}}$

๕ัँ

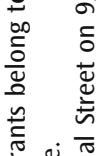

ஸ்

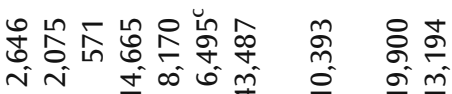

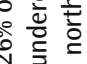

㐫恼.

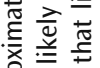

흫

苛

खेㅎํㅇ

$\geq$

言 虽

효응

웅 능

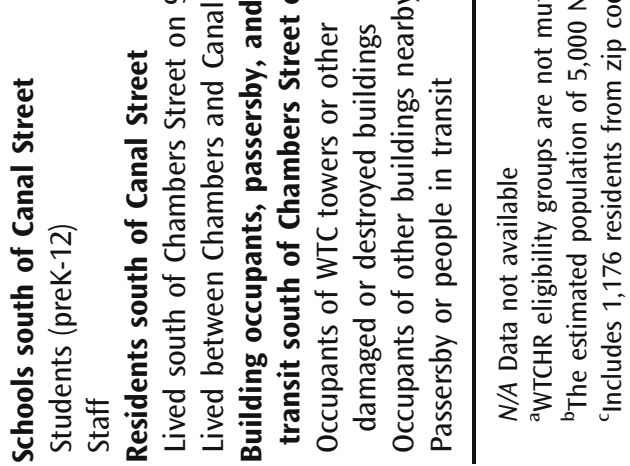




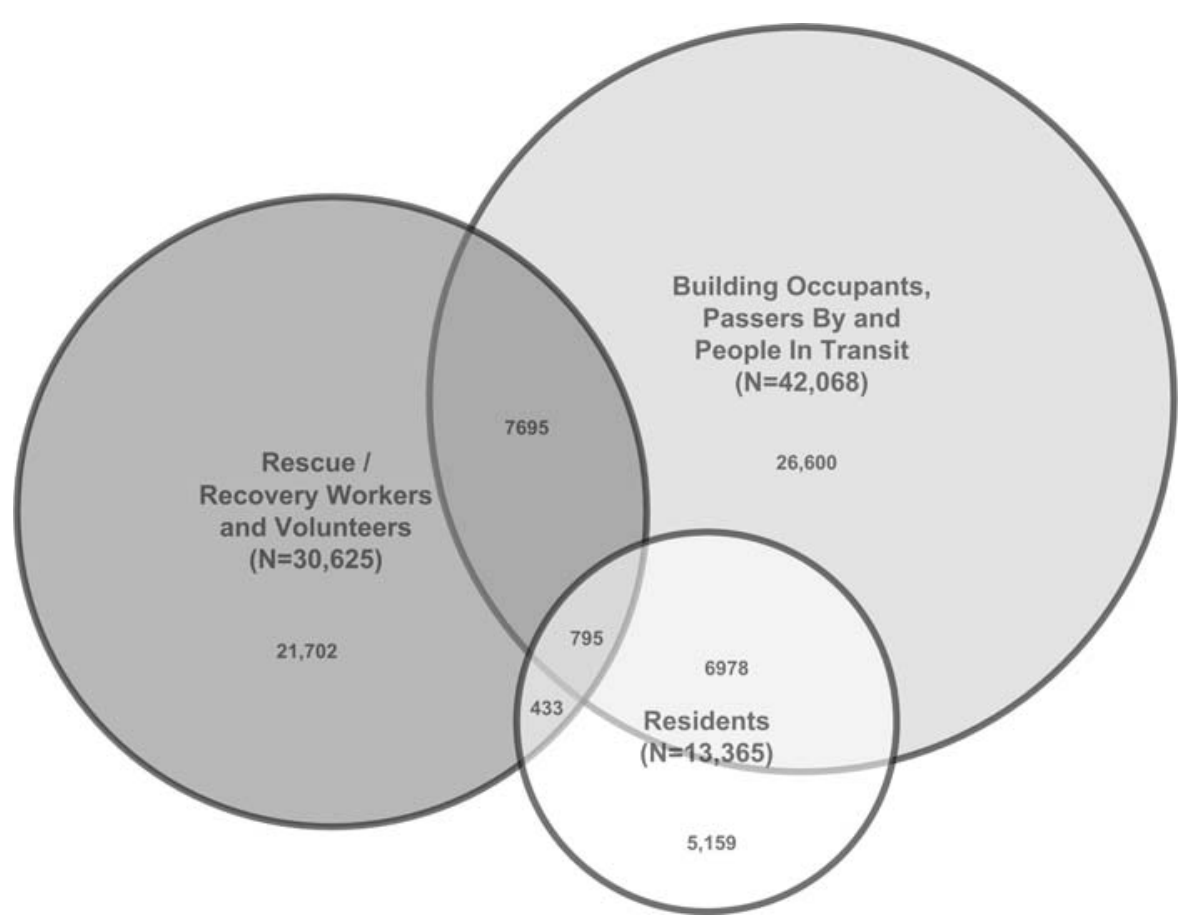

FIGURE 2. Overlap of major enrollment groups in the WTC Health Registry. Due to the difficulty of accurately representing more than three groups of greatly divergent size with a proportional circle Venn diagram, the smallest eligibility group, Students and School Staff $(n=2646)$, was excluded from this figure. Its overlap is described in the text.

York City on 9/11, including large numbers of Manhattan and Brooklyn residents. Manhattan resident enrollees were concentrated in four zip codes in lower Manhattan due to the nature of the WTCHR enrollment criteria.

Enrollees were predominantly white non-Hispanic, age 25-64 years, and had reported annual household incomes greater than $\$ 50,000$. The overall prevalence of current smoking among enrollees $(15.8 \%)$ was lower than the average prevalence among NYC adults in $2004(18.3 \%){ }^{39}$

More than half of all enrollees $(51 \%)$ reported being caught in the dust and debris cloud that resulted from the collapse of the WTC Towers 1 and 2. Building occupants $(71 \%)$ and school staff $(64 \%)$ were most likely to report dust cloud exposure, followed by students (52\%), residents $(50 \%)$, and workers $(37 \%)$. Enrollee location when first caught in the dust cloud on the morning of 9/11 was successfully geocoded using a combination of available location variables for 24,847 of the 36,452 (68\%) registrants who reported being caught in the dust cloud. Most $(91 \%)$ of the reported locations were in lower Manhattan (Figure 3) and heavily concentrated in the immediate vicinity of the WTC site and eastward. A small proportion of enrollees reported being present in more distant areas of Manhattan as well as in the city's other four boroughs, where the likelihood of being caught in the dust cloud on the morning of 9/11 was lower.

Approximately half of enrollees reported witnessing people fleeing from the dust cloud $(53 \%)$ or collapsing buildings (47\%). Many witnessed people injured or killed $(33 \%)$, people falling or jumping from a building $(29 \%)$, or an airplane hitting a 


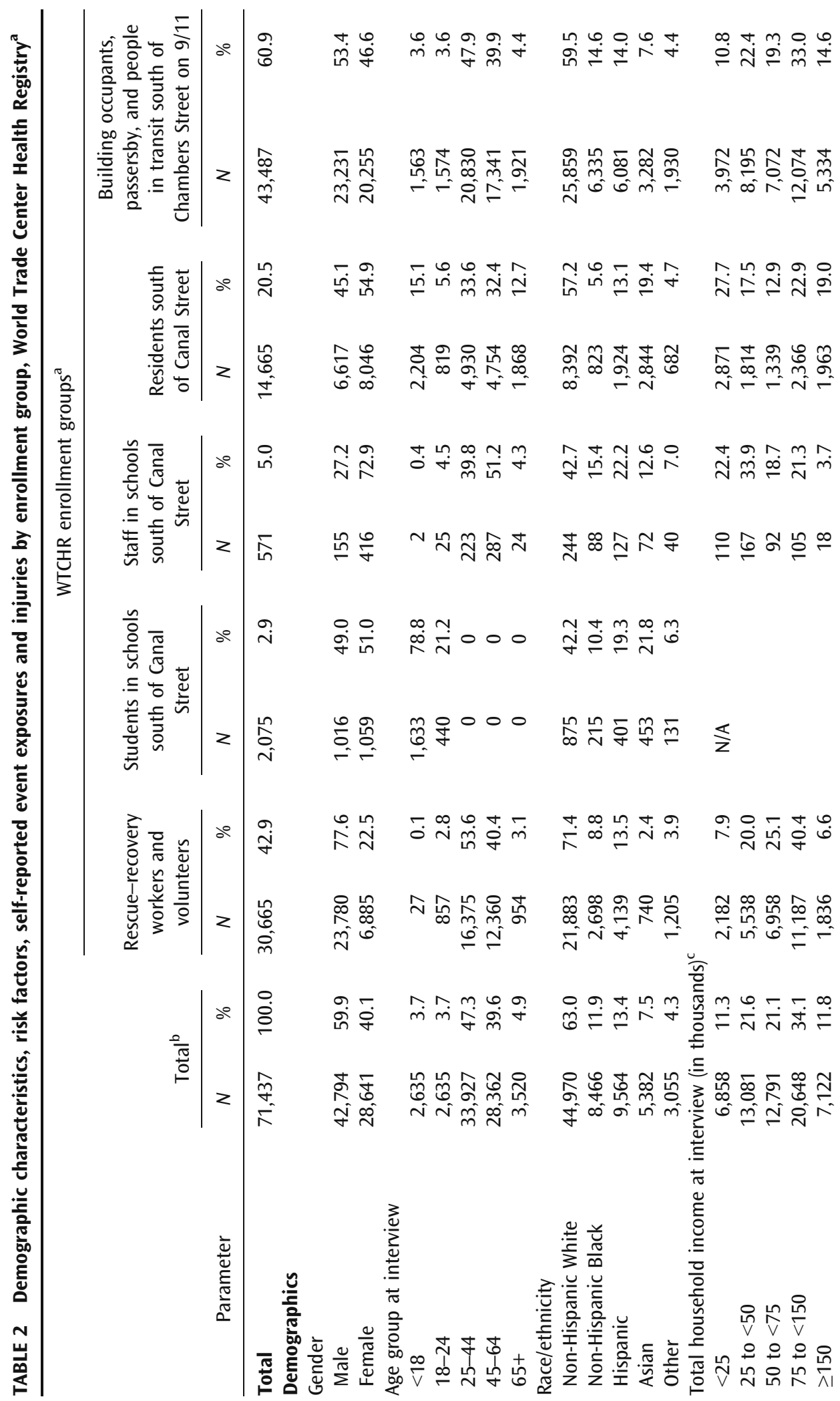




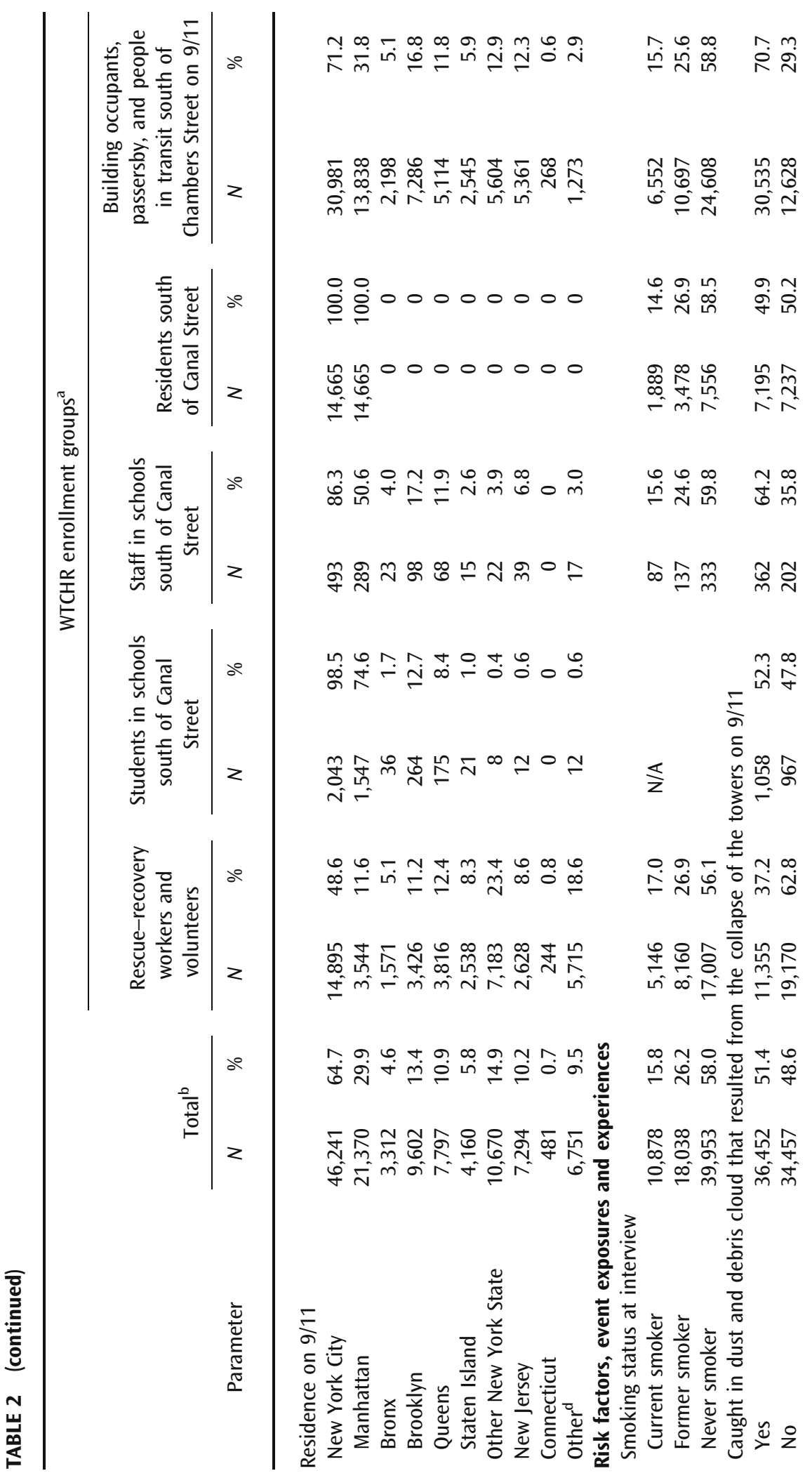




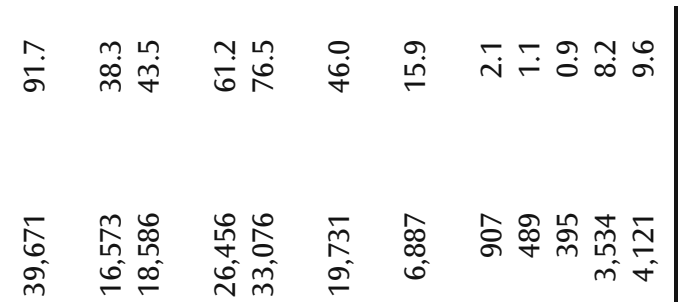

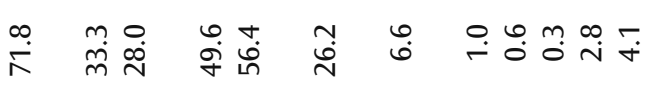

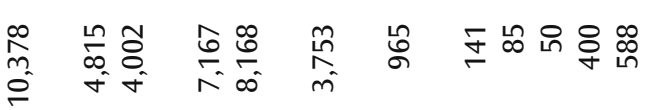

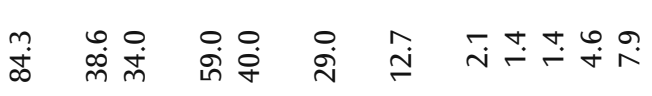

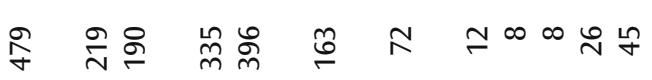

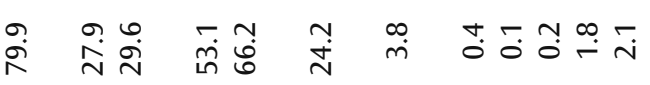

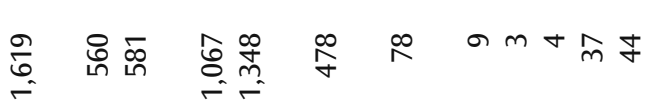

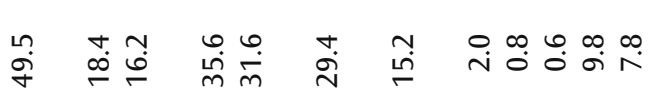

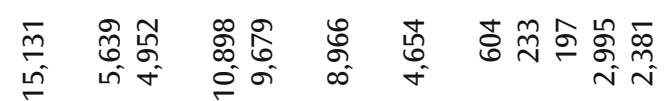

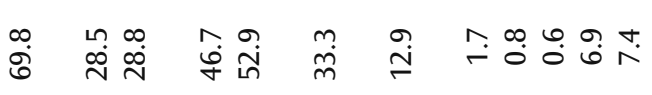

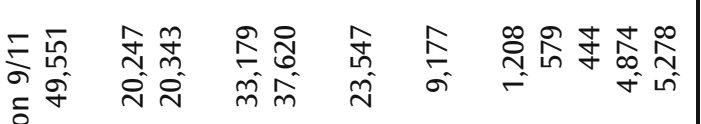

ญ

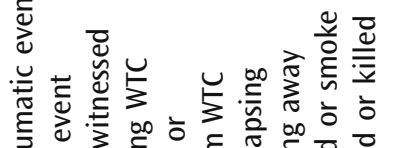

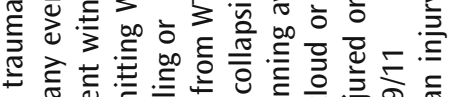

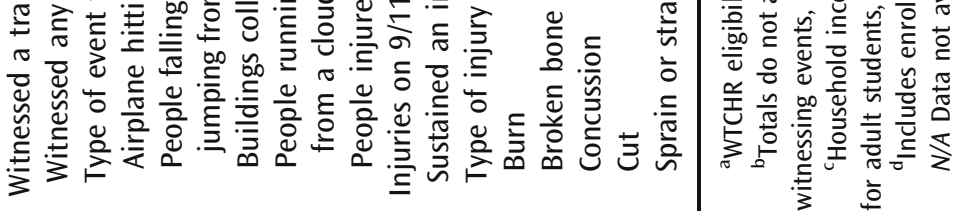




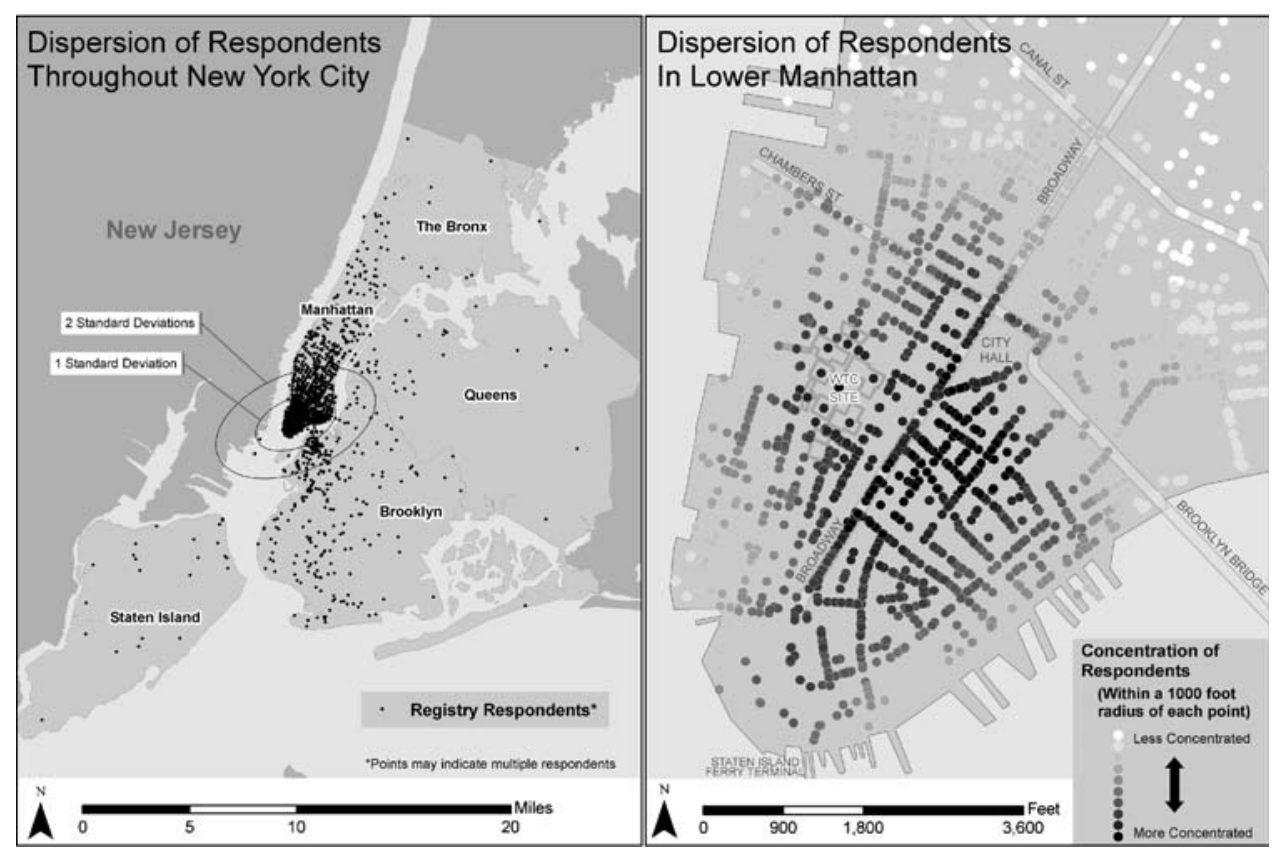

FIGURE 3. Enrollees' self-reported locations when first caught in the dust cloud on 9/11. Location data were successfully geocoded for 24,847 (68\%) of the registrants who reported being caught in the dust cloud.

building $(29 \%)$. Building occupants, passersby, and people in transit, school staff and school students were most likely to have reported witnessing any of these five types of traumatic events $(92 \%, 84 \%$, and $80 \%$, respectively). The prevalence of any type of injury sustained on $9 / 11$ ranged from $4 \%$ in students to $15 \%$ in workers and $16 \%$ in building occupants, passersby, and people in transit in lower Manhattan on the morning of $9 / 11$. The most commonly reported injuries were cuts and sprains or strains. Fewer enrollees reported more severe injuries such as burns, broken bones, and concussions.

More than 7,400 adult residents (61\%) reported that they evacuated their homes on or after $9 / 11$ (Table 3). Of those who evacuated, $9 \%$ returned as early as September 13th, 2001. Most (92\%) returned to their homes by the time of the interview. More than 24,000 enrollees reported that they had evacuated their workplace on $9 / 11$, with almost $70 \%$ of these evacuees returning to their workplace by the time of the interview. On average, workplace evacuees returned to lower Manhattan sooner than residents.

\section{Respiratory and Mental Health Outcomes}

Overall, $67 \%$ of adult enrollees reported any new or worsening respiratory symptom (persistent cough, shortness of breath, wheezing, throat irritation, or sinus irritation) after 9/11 (Table 3). The prevalence of new symptoms ranged from $32 \%$ for sinus irritation to $38 \%$ for shortness of breath; worsening symptoms were less frequently reported, ranging from $1.6 \%$ for persistent cough to $14 \%$ for sinus irritation (data not shown). Nearly $3 \%(n=1,967)$ of adult enrollees reported newly diagnosed asthma after 9/11. Overall, $16 \%$ of adult enrollees screened positive for current PTSD and $8 \%$ for serious psychological distress (SPD). 


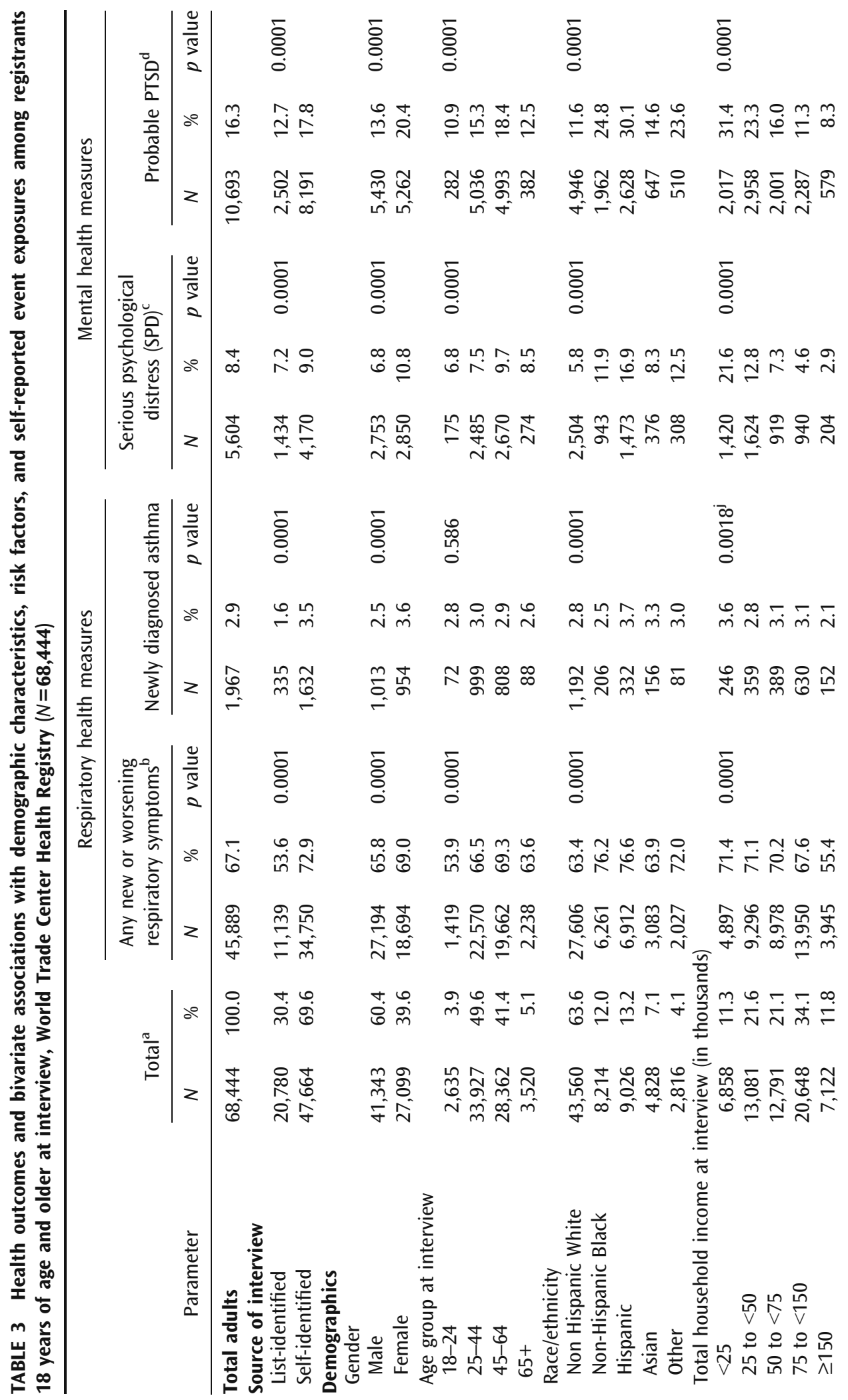




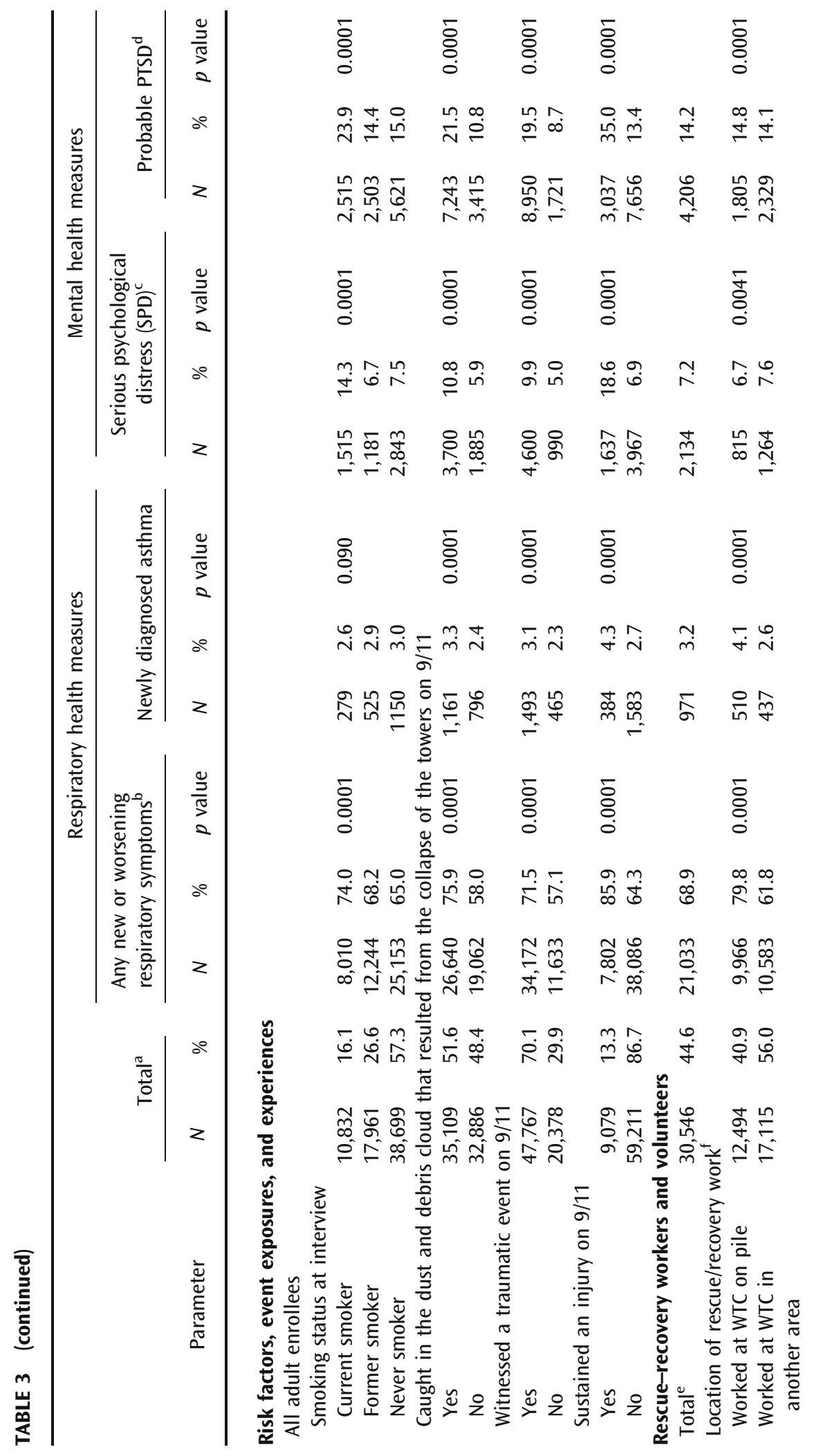


$\begin{array}{lll}\overline{8} & \stackrel{\circ}{0} & \overline{8} \\ 0 & 0 & 0\end{array}$

ळ̊

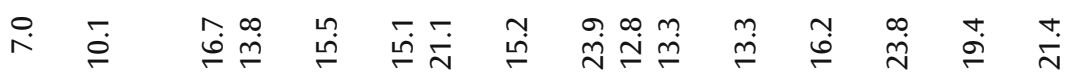

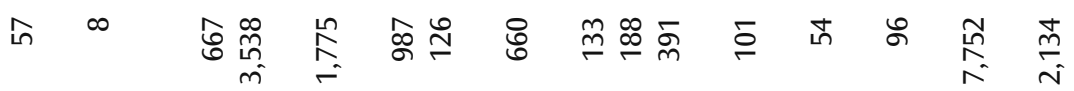

$\begin{array}{llll}m & \overline{0} & \overline{8} & \bar{\delta} \\ 0 & 0 & 0 & 0\end{array}$

n்

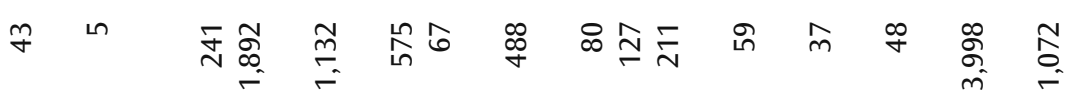

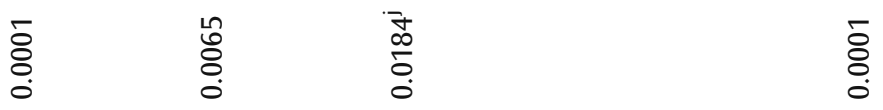

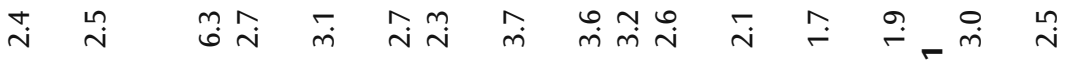

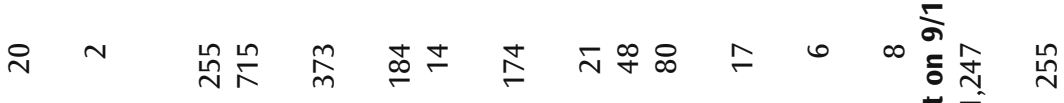
ळे

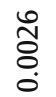
ळे

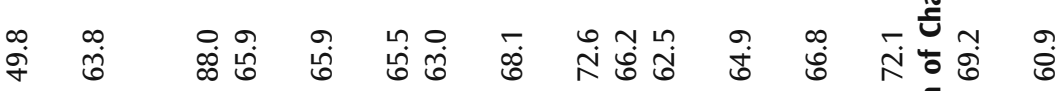

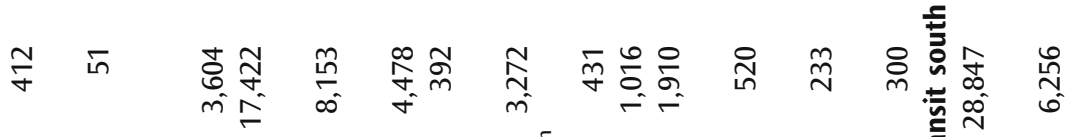

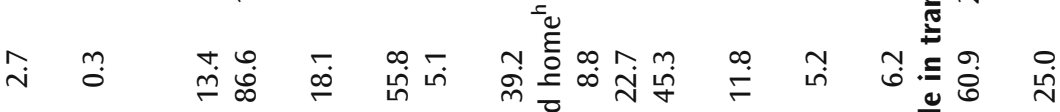

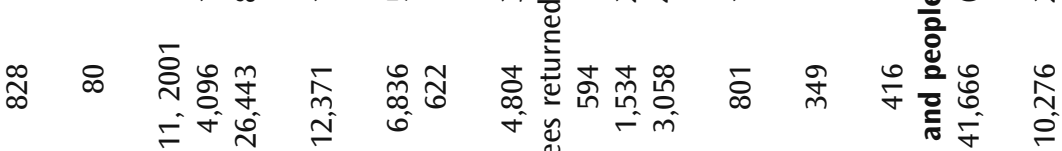

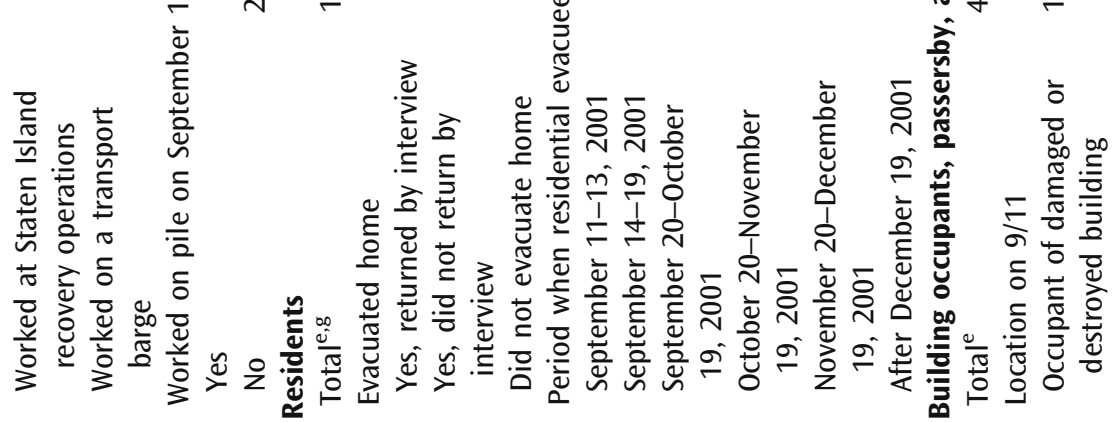




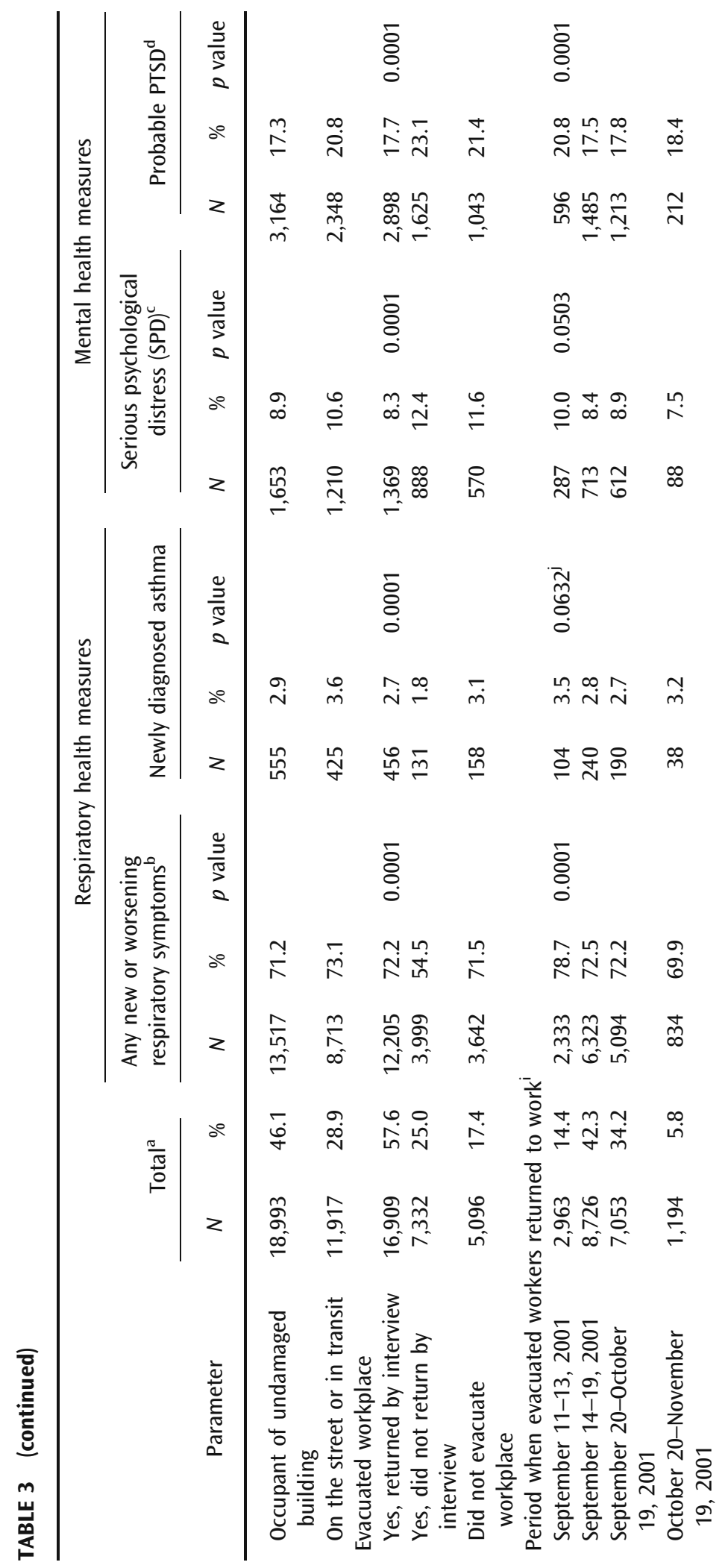




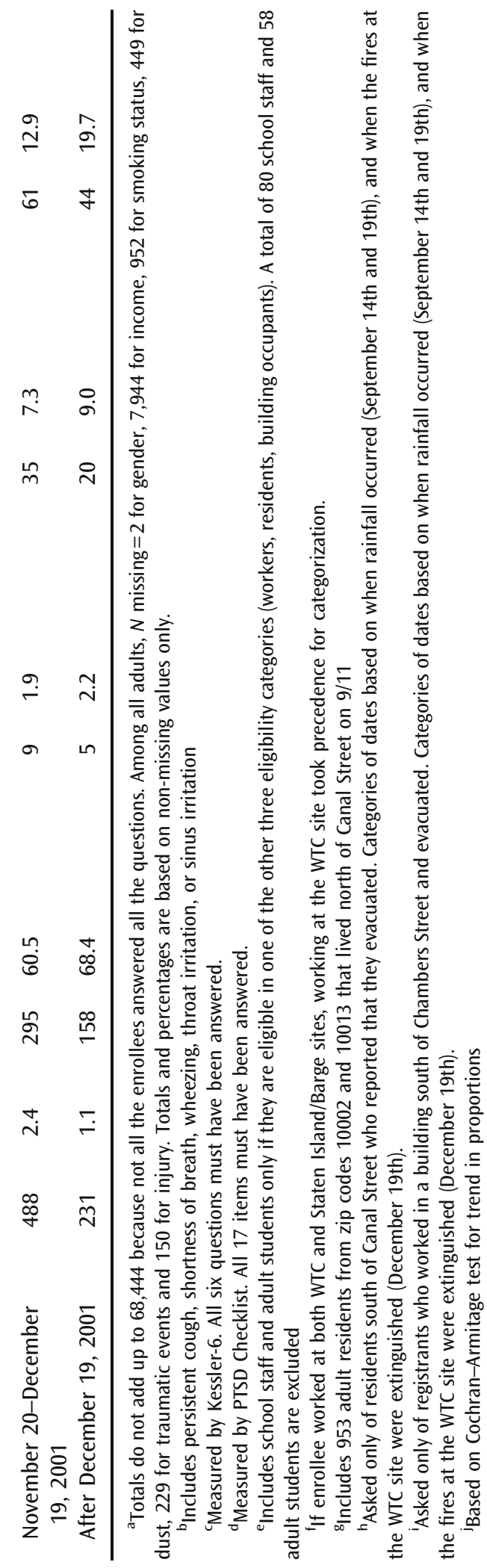


Demographic variables, smoking status, and source of interview were generally significantly associated with each of the respiratory and mental health outcomes (Table 3). Adult enrollees who were female, non-White, self-identified, or had lower incomes tended to have higher prevalence of a new or worsening respiratory symptom, newly diagnosed asthma, probable PTSD, and SPD.

Event experiences on 9/11 such as being in the dust cloud, witnessing a traumatic event, and sustaining an injury were also significantly associated with a higher likelihood of having either respiratory or mental health adverse outcomes. Each event experience was associated with an approximately twofold or greater increase in the prevalence of psychological distress and probable PTSD. Most strikingly, enrollees who sustained injuries were nearly three times more likely to develop probable PTSD than those who did not (35\% vs. $13 \%$ ).

Associations were also noted between 9/11 experiences and respiratory outcomes (Table 3). Of all enrollees, rescue and recovery workers and volunteers had the highest percentage of reported newly diagnosed asthma and the second highest percentage of respiratory symptoms. Location of rescue and recovery work, in particular, working on the WTC pile itself, was an important predictor of respiratory health outcomes, as was working on the pile on 9/11. Enrollees who worked on the WTC pile on 9/11 were more than twice as likely to have reported newly diagnosed asthma after $9 / 11$ as those who did not (6.3\% vs. $2.7 \%)$. Location of work was also associated with adverse mental health outcomes (Table 3 ).

Among eligibility groups, the prevalence of probable PTSD was highest among building occupants, passersby, and people in transit in lower Manhattan on the morning of $9 / 11(19 \%)$, followed by residents $(16 \%)$. Evacuation status and time returning home or to work were associated with both adverse respiratory and mental health outcomes. Residents and building occupants who did not evacuate their home or workplace were more likely than those who evacuated to report newly diagnosed asthma. Among evacuees, asthma was also more commonly reported by residents who returned home within the first week (by September 19th) than those who returned later $(3.3 \%$ vs $2.4 \%, p=0.046)$. Evacuees who had not returned to live or work in lower Manhattan had the highest prevalence of probable current PTSD, significantly higher than enrollees who had not evacuated their home or workplace and those who had returned to their home or workplace by the time of the interview.

\section{Estimated Burden of Health Problems among Adults}

Estimates of the total number of adults with symptoms or newly diagnosed illness after the attacks are shown in Table 4. Using data from the WTCHR, we estimate that among the previously estimated eligible population of 409,492 persons, between 124,800 and 232,200 exposed people experienced new or worsening respiratory symptoms after 9/11,3,800-12,600 had newly diagnosed asthma by 2 to 3 years after the event, 34,600-70,200 developed probable PTSD, and 9,70020,000 people experienced SPD.

\section{Children's Respiratory and Mental Health Outcomes}

Of the 3,184 enrollees under age 18 years on 9/11, most (69\%) were residents of lower Manhattan. Nearly half $(45 \%)$ of these children were caught in the dust cloud on $9 / 11$, half $(50 \%)$ had personally witnessed disturbing events, and $53 \%$ had at least one new or worsening respiratory symptom after 9/11. Eye irritation or eye 
TABLE 4 Estimates of total burden of illness among registrants 18 years of age and older, based on prevalence of reported health problems in the WTCHR and estimates of populations eligible for WTCHR enrollment ${ }^{a}$

\begin{tabular}{|c|c|c|c|}
\hline Parameter & Lower bound ${ }^{b}$ & Midpoint $^{c}$ & Upper bound ${ }^{d}$ \\
\hline \multicolumn{4}{|l|}{ Any new or worsening respiratory symptom } \\
\hline Rescue-recovery workers and volunteers & 32,300 & 41,200 & 61,800 \\
\hline $\begin{array}{l}\text { Building occupants, passersby, and people } \\
\text { in transit }\end{array}$ & 86,600 & 112,400 & 161,500 \\
\hline Residents south of Canal St. & 5,900 & 7,600 & 8,900 \\
\hline Total & 124,800 & 161,200 & 232,200 \\
\hline \multicolumn{4}{|l|}{ Newly diagnosed asthma } \\
\hline Rescue-recovery workers and volunteers & 1,100 & 1,600 & 3,700 \\
\hline $\begin{array}{l}\text { Building occupants, passersby, and people } \\
\text { in transit }\end{array}$ & 2,400 & 3,700 & 8,300 \\
\hline Residents south of Canal St. & 300 & 400 & 600 \\
\hline Total & 3,800 & 5,700 & 12,600 \\
\hline \multicolumn{4}{|l|}{ Serious psychological distress } \\
\hline Rescue-recovery workers and volunteers & 1,700 & 2,500 & 3,400 \\
\hline $\begin{array}{l}\text { Building occupants, passersby, and people } \\
\text { in transit }\end{array}$ & 7,700 & 11,400 & 16,000 \\
\hline Residents south of Canal St. & 300 & 400 & 600 \\
\hline Total & 9,700 & 14,300 & 20,000 \\
\hline \multicolumn{4}{|l|}{ Probable PTSD } \\
\hline Rescue-recovery workers and volunteers & 7,300 & 10,600 & 13,700 \\
\hline $\begin{array}{l}\text { Building occupants, passersby and people } \\
\text { in transit }\end{array}$ & 26,500 & 38,000 & 54,700 \\
\hline Residents south of Canal St. & 800 & 1,100 & 1,800 \\
\hline Total & 34,600 & 49,700 & 70,200 \\
\hline
\end{tabular}

${ }^{\mathrm{a} B}$ Burden estimates are rounded to the nearest hundred.

${ }^{\mathrm{b}}$ Lower bound estimate adjusts for the possibility that even among listed persons, those ill were $50 \%$ more likely to enroll in the WTCHR. The lower bound estimate is the product of the total population exposed and the ratio of $A$ to $B$, where $(A)$ is the number of list-identified persons who were ill and $(B)$ is the sum of the number of list-identified persons who were healthy $\times 1.5$ and the number of list-identified persons who were ill.

${ }^{c}$ Midpoint estimate is the product of the percent ill among list-identified persons and the total population exposed

${ }^{\mathrm{d}}$ Upper bound estimate is the product of the percent ill among self-identified persons and the total population exposed

injury was reported for $22 \%$ of children; other injuries on $9 / 11$ were reported for $3 \%$ (including sprains, lacerations, burns, broken bones, or concussions). For 180 children $(5.7 \%)$, asthma was newly diagnosed after $9 / 11$. Three percent of children met criteria for possible posttraumatic stress at interview. Dust cloud exposure was associated with newly diagnosed asthma. ${ }^{40}$ Posttraumatic stress symptoms were associated with dust cloud exposure and with witnessing disturbing events.

\section{DISCUSSION}

The attacks of $9 / 11$ had adverse health impacts far beyond the immediate deaths and injuries from the acute event. The WTC Health Registry, the largest postdisaster registry in U.S. history, is the best opportunity to measure the magnitude of these health problems. Our study estimates that more than 100,000 adults experienced new or worsening respiratory symptoms after $9 / 11$ and that tens of thousands of 
cases of probable PTSD and thousands of cases of newly diagnosed asthma developed in the first 2 to 3 years after the event. Our findings raise awareness that these adverse health impacts extended beyond workers involved in rescue and recovery to encompass building occupants, residents, passersby, and people in transit in lower Manhattan on 9/11. These findings also underscore the value of the WTCHR as a resource to inform health care services, project needs for affected populations, and link affected individuals to services.

Systematic measurement of 9/11 exposures identified that registry enrollees were heavily exposed to physical and psychological risks, including being caught in the dust cloud, witnessing traumatic events, and sustaining injuries. These exposures correlated strongly with health symptoms. National estimates of expected adult asthma incidence are limited and vary in their range (3-year rates range from $0.8 \%$ to $1.6 \%)$; all are two to four times lower than the reported asthma incidence among enrollees 2-3 years after 9/11. ${ }^{41-43}$ Symptoms compatible with PTSD were approximately four times higher than national estimates of current PTSD from disparate trauma sources $(16 \%$ vs. $4 \%){ }^{44}$ Among enrollees identified through lists, groups which may have been less subject to self-selection bias, PTSD $(12.7 \%)$ levels were substantially higher than expected background rates. New diagnosis of asthma in the list-identified group $(1.6 \%)$ was comparable to the higher end of the national estimate spectrum, but was significantly associated with reported disaster exposures (being caught in the dust cloud, sustaining an injury on 9/11).

To date, the WTCHR has a number of in-depth studies published that examine the health impacts on specific populations (Table 5). These studies give additional details on respiratory and mental health findings, as well as more detailed analyses of risk factors and the dose-response association between exposures and health outcomes. ${ }^{12,15,16,21,40}$ We found that self-reported new diagnosis of asthma was highest among rescue and recovery workers, particularly those working directly on the WTC pile. A previously published WTCHR study of asthma-free workers and volunteers who worked on the WTC site examined the impact of work-related exposures on new diagnosis of asthma and found early arrival time, duration of work on the WTC site, working directly on the pile, and being caught in the initial dust cloud to be independent predictors of developing the condition. ${ }^{12}$ Other focused studies of rescue and recovery workers have also identified that persons with more intense or prolonged exposure to the WTC collapse and immediate disaster site had more severe respiratory symptoms, conditions, or lung function decline..$^{8-11,45}$

Among lower Manhattan adult residents and office workers, asthma and new or worsening respiratory symptoms were more commonly reported among those who did not evacuate at all and those who returned early, in the first week after the attacks, compared to those who returned later. Few studies have examined exposures and health outcomes in lower Manhattan residents or office workers, but elevated respiratory symptoms have been reported elsewhere. ${ }^{46-49}$

Few postdisaster studies have addressed new diagnosis of asthma, and no previous disaster is directly comparable to the collapse of the WTC towers on 9/11. Asthma exacerbations have been reported in association with natural disasters, including wild land fires, earthquakes, hurricanes, and volcanic eruptions and wartime exposures to oil fire smoke. ${ }^{50-54}$ In the occupational setting, some multicase outbreaks have been described, including irritant-induced asthma among police responding to a roadside spill of chemicals used for polymerized plastic coatings, hospital staff following a spill of acetic acid, and those living or working near a spill of metam sodium pesticide. ${ }^{55-57}$ 


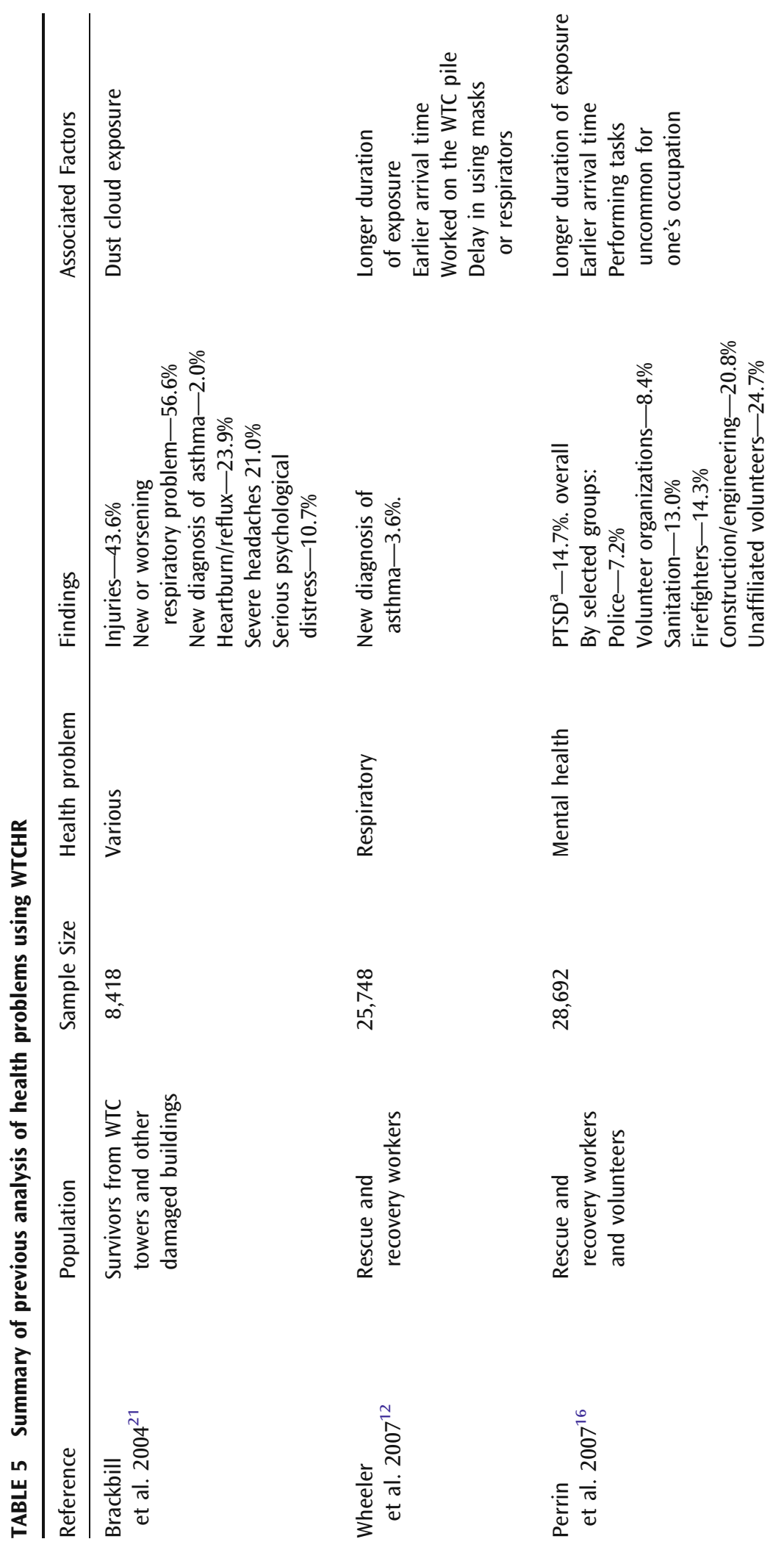




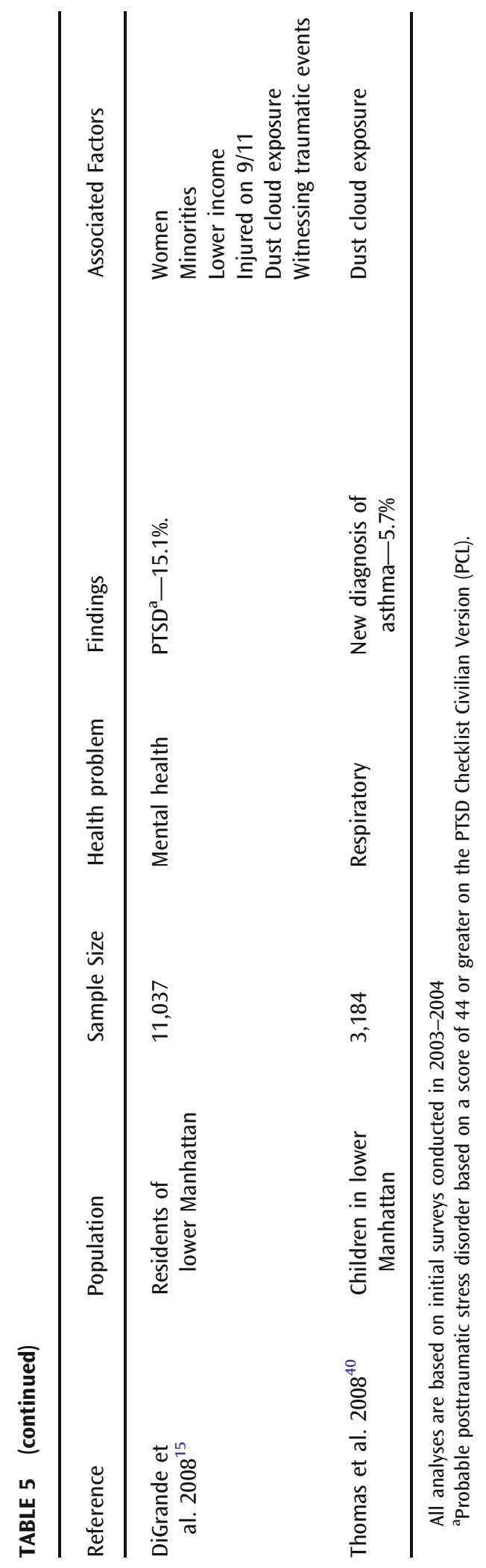


The prevalence estimates of current, probable PTSD among enrollees 2-3 years after the attacks were higher than those based on self-report from random digit dialed studies in New York City among Manhattan residents conducted 6 to 8 weeks after $9 / 11(7.5 \%)$, among all New York City adults conducted at 4 and 6 months post-9/11 (2.3 and $1.5 \%$, respectively), as well as national estimates for the general population after $9 / 11(4 \%) .{ }^{20,58-61}$ Studies done within the first year of other man-made disasters have reported PTSD prevalence in the range of $1 \%$ to $11 \%$ among the general population and $25-75 \%$ among survivors, including a prevalence of $34 \%$ among survivors of the Oklahoma City bombing. ${ }^{62-69}$ In our study, the PTSD prevalence in each WTCHR eligibility group at 2-3 years post-9/11 falls between these ranges reported for the general population and survivors of other disasters. This is likely due, in part, to the fact that lower Manhattan residents, building occupants, passersby, and people in transit as well as rescue and recovery workers experienced both direct and indirect exposures to 9/11. A WTCHR study of rescue and recovery workers found that those at highest risk of PTSD were in occupations least likely to have had prior disaster training or experience, including unaffiliated volunteers $(24.7 \%)$ and construction or engineering workers $(20.8 \%)$. Other risk factors included duration of work, earlier arrival, and performing activities uncommon for one's occupation (Table 5). ${ }^{16}$

Consistent with theories about the causes of PTSD, the prevalence of probable PTSD was higher among enrollees who reported direct exposures on 9/11 indicative of life threat such as sustaining an injury (35\%), being caught in the dust cloud $(22 \%)$, or witnessing a traumatic event $(20 \%)$. Our findings are consistent with known demographic risk factors for PTSD, including female gender, minority racial/ ethnic status, low-income, and middle age in adults. ${ }^{58,61,68,70-76}$ The relationship between income and PTSD was particularly strong, with persons reporting a household income less than $\$ 25,000$ having PTSD levels nearly four times as high as those reporting a household income of $\$ 150,000$ or greater. The other mental health outcome we measured among enrollees was SPD. While less specific in nature, SPD measures psychological distress that is quite severe, usually affecting one's functionality. ${ }^{24}$ The prevalence of probable SPD measured among registry enrollees 2-3 years after 9/11 was significantly higher than the citywide prevalence among New York City adult residents during a similar time period ( $8 \%$ compared to $5 \%$ in 2003). ${ }^{77}$

This study has important limitations. The first pertains to the issue of selection bias. Although extensive efforts were made to have a high level of participation in the registry and more than 70,000 persons chose to enroll, the percentage of the estimated eligible persons who enrolled in the registry was low $(17.4 \%)$, and most enrollees were self-identified. While there were no direct medical, legal, or financial benefits to enrolling in the registry, it is reasonable nonetheless to assume that persons experiencing symptoms were more likely to make the effort to enroll in the registry than those who remained symptom-free. The prevalence of health problems may thus have been overestimated, particularly among the self-identified enrollees. A related potential source of bias is differential enrollment of residents by evacuation status. However, eligible individuals who evacuated after 9/11 would also have been included in the recruitment list building effort, traced intensively in the locating effort by the survey vendor, and exposed potentially to the intensive media and outreach campaigns (e.g., bus, subway, ferry, newspaper, and radio ads).

While the registry is not fully representative, information is available on the population from which the enrolled participants came. Unlike case series studies, the 
degree of representativeness of registry findings can thus be estimated, and inferences can be made about disease rates; representativeness can be further improved by considering persons recruited from lists, who are less subject to self-selection bias.

A second major limitation pertains to the possibility of recall bias. The registry collected data 2-3 years after the event and relied on self-reported exposure and health information. Enrollees with greater exposure to the disaster may have been more likely to recall symptoms and connect symptoms to the disaster than enrollees with lesser exposure. A related limitation is that timing and severity of symptoms was not collected, and we were unable to distinguish symptoms that resolved immediately or by the time of interview from persistent ones. On the other hand, despite the lack of objective exposure information, we collected detailed information about occupation, location at the time of the event, and duration at high-impact locations that enable the development of proxy measures of exposure to dust or other risks that are less subject to recall bias.

In spite of these limitations, the WTCHR and this study provide a unique perspective on the health effects of the 9/11 disaster. By collecting systematic health information on a wide and diverse group of persons exposed to health risks, it offers among the best estimates of how many people were heavily exposed and the magnitude of adverse health effects. The resultant picture that emerges confirms that the World Trade Center disaster had substantial health implications for large numbers of people, including residents and building occupants who comprise understudied populations post-9/11. Registry data were used to inform the development of physician guidelines and the expansion of 9/11-related services for residents through city-funded programs, including a mental health benefits program and an Environmental Health Center of Excellence described in detail elsewhere (www.nyc.gov/9-11healthinfo).

This paper is the first to provide an overview of selected physical and mental health effects on affected adults within the first 2-3 years of the 9/11 attacks and aftermath. More focused studies are needed to fully investigate the relationship between exposures and health problems, and to characterize the severity and duration of the health effects. The World Trade Center Health Registry continues to track enrollees through periodic health surveys, in-depth studies and periodic matches to vital records, cancer registries, and other health data. It will continue to serve as a key resource to study the duration, scope, and severity of health impacts, identify subgroups for more in-depth studies, guide decisions about medical care and other services, and connect individual people to the specific services they need.

\section{ACKNOWLEDGMENT}

This research was supported by Cooperative Agreement Number U50/ATU272750 from the Agency for Toxic Substances and Disease Registry with additional funding from the CDC's National Center for Environmental Health. The contents of this article are solely the responsibility of the authors and do not necessarily represent the official views of the ATSDR. The manuscript underwent ATSDR external peer review.

\section{OPEN ACCESS}

This article is distributed under the terms of the Creative Commons Attribution Noncommercial License which permits any noncommercial use, distribution, and reproduction in any medium, provided the original author(s) and source are credited. 


\section{REFERENCES}

1. Murphy J, Brackbill RM, Thalji L, Dolan M, Pulliam P, Walker DJ. Measuring and maximizing coverage in the World Trade Center Health Registry. Stat Med. 2007;26 (8):1688-1701. doi:10.1002/sim.2806.

2. Landrigan PJ, Lioy PJ, Thurston G, et al. Health and environmental consequences of the world trade center disaster. Environ Health Perspect. 2004;112(6):731-739.

3. Lioy PJ, Weisel CP, Millette JR. Characterization of the dust/smoke aerosol that settled east of the World Trade Center (WTC) in Lower Manhattan after the collapse of the WTC 11 September 2001. Environ Health Perspect. 2002;110(7):703-714.

4. Centers for Disease Control and Prevention. Physical health status of World Trade Center rescue and recovery workers and volunteers. New York City: CDC; 2004.

5. Banauch GI, Hall C, Weiden M, Cohen H, Aldrich T, Christodoulou V. Pulmonary function after exposure to the World Trade Center collapse in the New York City Fire Department. Am J Respir Crit Care Med. 2006;174(3):312-319. doi:10.1164/rccm.200511-1736OC.

6. Feldman DM, Baron SL, Bernard BP, Lushniak B, Banauch G, Arcentales N. Symptoms, respirator use, and pulmonary function changes among New York City firefighters responding to the World Trade Center disaster. Chest. 2004;125(4):1256-1264. doi:10.1378/chest.125.4.1256.

7. Levin S, Herbert R, Skloot G, et al. Health effects of World Trade Center site workers. Am J Ind Med. 2002;42(6):545-547. doi:10.1002/ajim.10154.

8. Herbert R, Moline J, Skloot G, et al. The World Trade Center disaster and the health of workers: five-year assessment of a unique medical screening program. Environ Health Perspect. 2006;114(12):1853-1858.

9. Herbstman JB, Frank R, Schwab M, et al. Respiratory effects of inhalation exposure among workers during the clean-up effort at the World Trade Center disaster site. Environ Res. 2005;99(1):85-92. doi:10.1016/j.envres.2004.08.010.

10. Prezant DJ, Weiden M, Banauch G, McGuinness G, Rom W, Aldrich T. Cough and bronchial responsiveness in firefighters at the World Trade Center site. N Engl J Med. 2002;347(11):806-815. doi:10.1056/NEJMoa021300.

11. Skloot G, Goldman M, Fischler D, Goldman C, Schechter C, Levin S. Respiratory symptoms and physiologic assessment of ironworkers at the World Trade Center Disaster site. Chest. 2004;125(4):1248-1255. doi:10.1378/chest.125.4.1248.

12. Wheeler K, McKelvey W, Thorpe L, et al. Asthma diagnosed after 11 September 2001 among rescue and recovery workers: findings from the World Trade Center Health Registry. Environ Health Perspect. 2007;115(11):1584-1590.

13. Gavett SH, Haykal-Coates N, Highfill JW, et al. World Trade Center fine particulate matter causes respiratory tract hyperresponsiveness in mice. Environ Health Perspect. 2003;111(7):981-991.

14. Adams RE, Boscarino JA, Galea S. Social and psychological resources and health outcomes after the World Trade Center Disaster. Soc Sci Med. 2006;62(1):176-188. doi:10.1016/j.socscimed.2005.05.008.

15. DiGrande L, Perrin MA, Thorpe LE, et al. Posttraumatic stress symptoms, PTSD, and risk factors among lower Manhattan residents 2-3 years after the September 11, 2001 terrorist attacks. J Trauma Stress. 2008;21(3):264-273. doi:10.1002/jts.20345.

16. Perrin MA, DiGrande L, Wheeler K, Thorpe L, Farfel M, Brackbill R. Differences in PTSD prevalence and associated risk factors among World Trade Center disaster rescue and recovery workers. Am J Psychiatry. 2007;164(9):1385-1394. doi:10.1176/appi. ajp.2007.06101645.

17. Yehuda R, Hyman SE. The impact of terrorism on brain, and behavior: what we know and what we need to know. Neuropsychopharmacology. 2005;30(10):1773-1780.

18. Fairbrother G, Galea S. Terrorism, mental health, and September 11, lessons learned about providing mental health services to a traumatized population. The Century Foundation Report. 2005. 
19. Schuster MA, Stein BD, Jaycox LH. A national survey of stress reactions after the September 11, 2001 terrorist attacks. N Engl J Med. 2001;345(20):1507-1512. doi:10.1056/NEJM200111153452024.

20. Silver RC, Holman EA, McIntosh DN, Poulin M, Gil-Rivas V. Nationwide longitudinal study of psychological responses to September 11. JAMA. 2002;288(10):1235-1244. doi:10.1001/jama.288.10.1235.

21. Brackbill RM, Thorpe LE, DiGrande L, et al. Surveillance for World Trade Center disaster health effects among survivors of collapsed and damaged buildings. MMWR Surveill Summ. 2006;55(2):1-18.

22. Nelson DE, Holtzman D, Bolen J, Stanwyck CA, Mack KA. Reliability and validity of measures from the Behavioral Risk Factor Surveillance System (BRFSS). Soz Praventivmed. 2001;46(Suppl 1):S3-S42.

23. Kessler RC, Andrews G, Colpe L, et al. Short screening scales to monitor population prevalences and trends in non-specific psychological distress. Psychol Med. 2002;32 (6):959-976. doi:10.1017/S0033291702006074.

24. Kessler RC, Barker PR, Colpe LJ, et al. Screening for serious mental illness in the general population. Arch Gen Psychiatry. 2003;60(2):184-189. doi:10.1001/archpsyc.60.2.184.

25. Weathers F, Ford J. Psychometric properties of the PTDS checklist. [PCL-C, PCL-S, PCLM, PCL-PR]. Measurement of Stress, Trauma and Adaptation. 1996.

26. Dobie DJ, Kivlahan DR, Maynard C, et al. Screening for post-traumatic stress disorder in female Veteran's Affairs patients: validation of the PTSD checklist. Gen Hosp Psychiatry. 2002;24(6):367-374. doi:10.1016/S0163-8343(02)00207-4.

27. Lang AJ, Laffaye C, Satz LE, Dresselhaus TR, Stein MB. Sensitivity and specificity of the PTSD checklist in detecting PTSD in female veterans in primary care. J Trauma Stress. 2003;16(3):257-264. doi:10.1023/A:1023796007788.

28. Blanchard EB, Hickling EJ, Barton KA, Taylor AE, Loos WR, Jones-Alexander J. Oneyear prospective follow-up of motor vehicle accident victims. Behav Res Ther. 1996;34 (10):775-786. doi:10.1016/0005-7967(96)00038-1.

29. Andrykowski MA, Cordova MJ, Studts JL, Miller TW. Posttraumatic stress disorder after treatment for breast cancer: prevalence of diagnosis and use of the PTSD ChecklistCivilian Version (PCL-C) as a screening instrument. J Consult Clin Psychol. 1998;66 (3):586-590. doi:10.1037/0022-006X.66.3.586.

30. Smith MY, Redd W, DuHamel K, Vickberg SJ, Ricketts P. Validation of the PTSD Checklist-Civilian Version in survivors of bone marrow transplantation. J Trauma Stress. 1999;12(3):485-499. doi:10.1023/A:1024719104351.

31. Ruggiero KJ, Del Ben K, Scotti JR, Rabalais AE. Psychometric properties of the PTSD Checklist-Civilian Version. J Trauma Stress. 2003;16(5):495-502. doi:10.1023/ A:1025714729117.

32. North C, Pfefferbaum B. Research on the mental health effects of terrorism. JAMA. 2002;288(5):633-636. doi:10.1001/jama.288.5.633.

33. Hoven CW, Duarte CS, Lucas CP, et al. Psychopathology among New York city public school children 6 months after September 11. Arch Gen Psychiatry. 2005;62(5):545-552. doi:10.1001/archpsyc.62.5.545.

34. Lioy P, Pellizzari E, Prezant D. World Trade Center aftermath and its effects on health: understanding and learning through human-exposure science. Environ Sci Technol. 2006;40(22):6876-6885.

35. Ebdon D. Statistics in Geography. Worcester, Great Britain: Basil Blackwell; 1988.

36. Mitchell A. The ESRI Guide to GIS Analysis: Spatial Measurements and Statistics. Vol 2. Redlands, CA: ESRI Press; 2005.

37. Statistical Analysis System (Version 9.1). Cary, NC: SAS; 2005.

38. Chow S, Rodgers P. Extended abstract: Constructing area-proportional Venn and Euler diagrams with three circles. Euler Diagrams Workshop. Paris; 2005.

39. NYCDOHMH. NYC Community Health Survey. New York City: New York City Department of Health and Mental Hygiene; 2004. 
40. Thomas P, Brackbill R, Thalji L, et al. Respiratory and Other Health Effects Reported in Children Exposed to the World Trade Center Disaster of September 11, 2001: Environ Health Perspect. doi:10.1289/ehp.11205.

41. Rose D, Mannino DM, Leaderer BP. Asthma prevalence among US adult, 1998-2000: role of Puerto Rican ethnicity and behavioral and geographic factors. Am J Public Health. 2006;96(5):880-888. doi:10.2105/AJPH.2004.050039.

42. Rudd RA, Moorman JE. Asthma incidence: data from the National Health Interview Survey, 1980-1996. J Asthma. 2007;44(1):65-70. doi:10.1080/02770900601125896.

43. Sama SR, Hunt PR, Cirillo CI, et al. A longitudinal study of adult-onset asthma incidence among HMO members. Environ Health. 2003;2(1):10. doi:10.1186/1476069X-2-10.

44. Kessler RC, Chiu WT, Demler O, Merikangas KR, Walters EE. Prevalence, severity, and comorbidity of 12-month DSM-IV disorders in the National Comorbidity Survey Replication. Arch Gen Psychiatry. 2005;62(6):617-627. doi:10.1001/archpsyc. 62.6.617.

45. Salzman SH, Moosavy FM, Miskoff JA, Friedmann P, Fried G, Rosen MJ. Early respiratory abnormalities in emergency services police officers at the World Trade Center site. J Occup Environ Med. 2004;46(2):113-122. doi:10.1097/01.jom.0000111612.68916.d0.

46. Trout D, Nimgade A, Mueller C, Hall R, Earnest GS. Health effects and occupational exposures among office workers near the World Trade Center disaster site. J Occup Environ Med. 2002;44:601-605. doi:10.1097/00043764-200207000-00003.

47. Reibman J, Lin S, Hwang SA, et al. The World Trade Center residents' respiratory health study: new-onset respiratory symptoms and pulmonary function. Environ Health Perspect. 2005;113(4):406-411.

48. Lin S, Reibman J, Bowers JA, et al. Upper respiratory symptoms and other health effects among residents living near the World Trade Center Site after September 11, 2001. Am J Epidemiol. 2005;162(6):499-507. doi:10.1093/aje/kwi233.

49. Lin S, Jones R, Reibman J, Bowers J, Fitzgerald EF, Hwang SA. Reported respiratory symptoms and adverse home conditions after 9/11 among residents living near the World Trade Center. J Asthma. 2007;44(4):325-332. doi:10.1080/02770900701344181.

50. Viswanathan S, Eria L, Diunugala N, Johnson J, McClean C. An analysis of effects of San Diego wildfire on ambient air quality. J Air Waste Manag Assoc. 2006;56(1):56-67.

51. Tomita K, Hasegawa Y, Watanabe M, Sano H, Hitsuda Y, Shimizu E. The Totton-Ken Seibu earthquake and exacerbation of asthma in adults. J Med Invest. 2005;52(1-2):8084. doi:10.2152/jmi.52.80.

52. Bernstein RS, Baxter PJ, Falk H, Ing R, Foster L, Frost F. Immediate public health concerns and actions in volcanic eruptions: lessons from the Mount St. Helens eruptions, May 18-October 18, 1980. Am J Public Health. 1986;76(3 Suppl):25-37.

53. Baxter PJ, Ing R, Falk H, Plikaytis B. Mt. St. Helens eruptions: the acute respiratory effects of volcanic ash in a North American community. Arch Environ Health. 1983;38 (3):138-143.

54. Cowan DN, Lange JL, Heller J, Kirkpatrick J, DeBarey S. A case-control study of asthma among US Army Gulf War veterans and modeled exposure to oil well fire smoke. Mil Med. 2002;167(9):777-782.

55. Promisloff RA, Lenchner GS, Phan A, Cichelli AV. Reactive airway dysfunction syndrome in three police officers following a roadside chemical spill. Chest. 1990;98(4):928-929. doi:10.1378/chest.98.4.928.

56. Kern DG. Outbreak of the reactive airways dysfunction syndrome after a spill of glacial acetic acid. Am Rev Respir Dis. 1991;144(5):1058-1064.

57. Cone JE, Wugofski L, Balmes JR, et al. Persistent respiratory health effects after a metam sodium pesticide spill. Chest. 1994;106(2):500-508. doi:10.1378/chest.106.2.500.

58. Galea S, Ahern J, Resnick H, et al. Psychosocial sequelea of the September 11th terrorist attacks in New York City. N Engl J Med. 2002;346:982-987. doi:10.1056/NEJMsa 013404. 
59. Galea S, Vlahov D, Resnick H, et al. Trends of probable posttraumatic stress disorder in New York City after the September 11 terrorist attacks. Am J Epidemiol. 2003;158 (6):514-524. doi:10.1093/aje/kwg187.

60. Schlenger WE, Caddell JM, Ebert L, et al. Psychological reactions to terrorist attacks: findings from the National Study of Americans' Reactions to September 11. JAMA. 2002;288(5):581-588. doi:10.1001/jama.288.5.581.

61. Neria Y, Gross R, Olfson M, et al. Posttraumatic stress disorder in primary care one year after the 9/11 attacks. Gen Hosp Psychiatry. 2006;28(3):213-222. doi:10.1016/j. genhosppsych.2006.02.002.

62. Havenaar JM, Rumyantzeva GM, van den Brink W, et al. Long-term mental health effects of the Chernobyl disaster: an epidemiologic survey in two former Soviet regions. Am J Psychiatry. 1997;154(11):1605-1607.

63. Palinkas LA, Petterson JS, Russell J, Downs MA. Community patterns of psychiatric disorders after the Exxon Valdez oil spill. Am J Psychiatry. 1993;150(10):1517-1523.

64. Brooks N, McKinlay W. Mental health consequences of the Lockerbie disaster. J Trauma Stress. 1992;5(4):527-543.

65. Dooley E, Gunn J. The psychological effects of disaster at sea. Br J Psychiatry. 1995;167 (2):233-237.

66. Green BL, Lindy JD, Grace MC, Leonard AC. Chronic posttraumatic stress disorder and diagnostic comorbidity in a disaster sample. J Nerv Ment Dis. 1992;180(12):760-766. doi:10.1097/00005053-199212000-00004.

67. Selly C, King E, Peveler R, Osola K, Martin N, Thompson C. Post-traumatic stress disorder symptoms and the Clapham rail accident. Br J Psychiatry. 1997;171:478-482.

68. North CS, Nixon SJ, Shariat S, et al. Psychiatric disorders among survivors of the Oklahoma City bombing. JAMA. 1999;282(8):755-762. doi:10.1001/jama.282.8.755.

69. Smith DW, Christiansen EH, Vincent R, Hann NE. Population effects of the bombing of Oklahoma City. J Okla State Med Assoc. 1999;92(4):193-198.

70. Kukla RA, Schlaenger WE, Fairbank JA, et al. Trauma and the Vietnam War Generation: Report of Findings from the National Vietnam Veterans Readjustment Survey. New York: Brunner/Mazel; 1990.

71. Ortega AN, Rosenheck R. Posttraumatic stress disorder among Hispanic Vietnam veterans. Am J Psychiatry. 2000;157(4):615-619. doi:10.1176/appi.ajp.157.4.615.

72. Penk WE, Robinowitz R, Black J, et al. Ethnicity: post-traumatic stress disorder (PTSD) differences among black, white, and Hispanic veterans who differ in degrees of exposure to combat in Vietnam. J Clin Psychol. 1989;45(5):729-735.

73. Pole N, Best SR, Weiss DS, et al. Effects of gender and ethnicity on duty-related posttraumatic stress symptoms among urban police officers. J Nerv Ment Dis. 2001;189 (7):442-448. doi:10.1097/00005053-200107000-00005.

74. Norris FH, Friedman MJ, Watson PJ. 60,000 disaster victims speak: Part II. Summary and implications of the disaster mental health research. Psychiatry. 2002;65(3):240-260. doi:10.1521/psyc.65.3.240.20169.

75. Kessler RC, Sonnega A, Bromet E, Hughes M, Nelson C. Posttraumatic stress disorder in the National Comorbidity Survey. Arch Gen Psychiatry. 1995;52(12):1048-1060.

76. Breslau N, Davis GC, Andreski P, Peterson EL, Schultz LR. Sex differences in posttraumatic stress disorder. Arch Gen Psychiatry. 1997;54(11):1044-1048.

77. NYCDOHMH. NYC Community Health Survey. New York City: New York City Department of Health and Mental Hygiene; 2003. 